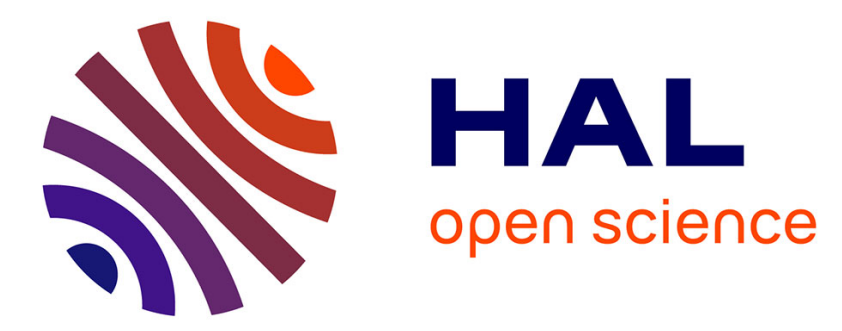

\title{
In Vivo Analysis of Proprioceptive Coding and Its Antidromic Modulation in the Freely Behaving Crayfish
}

Didier Le Ray, Denis Combes, Cyril Dejean, Daniel Cattaert

\section{To cite this version:}

Didier Le Ray, Denis Combes, Cyril Dejean, Daniel Cattaert. In Vivo Analysis of Proprioceptive Coding and Its Antidromic Modulation in the Freely Behaving Crayfish. Journal of Neurophysiology, 2005, 94 (2), pp.1013-1027. 10.1152/jn.01255.2004 . hal-02347082

\section{HAL Id: hal-02347082 \\ https://hal.science/hal-02347082}

Submitted on 7 Nov 2019

HAL is a multi-disciplinary open access archive for the deposit and dissemination of scientific research documents, whether they are published or not. The documents may come from teaching and research institutions in France or abroad, or from public or private research centers.
L'archive ouverte pluridisciplinaire HAL, est destinée au dépôt et à la diffusion de documents scientifiques de niveau recherche, publiés ou non, émanant des établissements d'enseignement et de recherche français ou étrangers, des laboratoires publics ou privés. 


\section{In vivo analysis of proprioceptive coding and its antidromic modulation in the freely behaving crayfish.}

by

Didier Le Ray ${ }^{1}$, Denis Combes ${ }^{1}$, Cyril Déjean ${ }^{1}$ and Daniel Cattaert

Laboratoire de Neurobiologie des Réseaux, CNRS-UMR 5816

Université Bordeaux 1, Avenue des Facultés 33405 Talence, France.

Present address:

${ }^{1}$ Laboratoire de Physiologie et Physiopathologie de la Signalisation Cellulaire, CNRS-UMR 5543, Université Victor Ségalen, BP 22, 146 rue Léo Saignat 33076 Bordeaux cedex, France

Running title: Sensory nerve activities in the freely moving crayfish

Text pages: 24. Figures: 9. Tables: 0 .

Abstract: 236. Introduction: 394. Discussion: 1682.

Corresponding author:

Dr. Daniel Cattaert. CNRS-UMR 5816, Université Bordeaux 1, Bât. B2-Biologie, Avenue des Facultés 33405 Talence, France.

Tel: 33 (0)5 4000 2567; Fax: 33 (0)5 4000 2561; E-mail: d.cattaert@lnr.u-bordeaux1.fr

Acknowledgments: This work was supported by the Centre National de la Recherche Scientifique (CNRS), and the ACI "Neurosciences integratives et computationnelles $n^{\circ} 32^{\prime}$ from the Ministère de l'Enseignement Supérieur et de la Recherche (France). The authors are grateful to Mr. L. Parra-Iglesias for nursing intact and operated crayfishes, and Drs. J. Einum and J. Simmers for helpful comments and for improving the English version. 


\begin{abstract}
Although sensory nerves in vitro are known to convey both orthodromic (sensory) and antidromic (putatively modulating) action potentials, in most cases very little is known about their bidirectional characteristics in intact animals. Here, we have investigated both the sensory coding properties and antidromic discharges that occur during real walking in the freely behaving crayfish. The activity of the sensory nerve innervating the proprioceptor $\mathrm{CBCO}$, a chordotonal organ that monitors both angular movement and position of the coxobasipodite (CB) joint, which is implicated in vertical leg movements, was recorded chronically along with the electromyographic activity of the muscles that control $\mathrm{CB}$ joint movements. Two wire electrodes placed on the sensory nerve were used to discriminate orthodromic from antidromic action potentials and, thus allowed for analysis of both sensory coding and antidromic discharges. A distinction is proposed between three main classes of sensory neuron, according to their firing in relation to levator muscle activity during free walking. In parallel, we describe two types of antidromic activity: one produced exclusively during motor activity and a second produced both during and in the absence of motor activity. A negative correlation was found between the activity of sensory neurons in each of the three classes and identified antidromic discharges during walking. Finally, a state-dependent plasticity of $\mathrm{CBCO}$ nerve activity has been found by which the distribution of sensory orthodromic and antidromic activity changes with the physiological state of the biomechanical apparatus.
\end{abstract}

Keywords: Sensory coding; Antidromic conduction; State-dependent plasticity; Proprioception; Locomotion; Chordotonal organ; Invertebrate; In vivo 


\section{INTRODUCTION}

During walking, various sensory receptors continually supply central locomotor networks with information about changes in the external environment and limbs position and movement. In particular, proprioceptors play a crucial role in the direct adjustment of motor commands to various constraints applied to the biomechanical system (Loeb 1987; Hasan and Stuart 1988; Duysens et al. 2000; Cattaert and Le Ray 2001). However, depending on the activity in which the motor system is engaged, sensory information is subject to considerable presynaptic modulation before reaching its postsynaptic targets (for recent reviews, see: McCrea 2001; Rudomin 2002). In crayfish for example, both long-lasting enhancement (Le Ray and Cattaert 1999) and rapid, short-lasting presynaptic inhibition (Sillar and Skorupski 1986; Cattaert et al. 1992; Cattaert and Le Ray 1998) were described in sensorymotor loops implicated in locomotor control. Bursts of antidromic action potentials, which sometimes accompany presynaptic inhibitory regulation (Dubuc et al. 1985, 1988; Gossard et al. 1991; Cattaert et al. 2001) and are conveyed from the central nervous system toward the peripheral sensory organ, were found to alter the coding properties of limbs proprioceptors in crayfish in vitro (Bévengut et al. 1997; Cattaert and Bévengut 2002) as well as in vertebrates (Slesinger and Bell 1985; Duenas et al. 1990; Gossard et al. 1999). However, whether such antidromic control has functional significance in intact animals and whether it is subjected to behavioral constraints remains to be investigated.

To address these points, the electroneurographic activity of the sensory nerve innervating the coxo-basipodite chordotonal organ $(\mathrm{CBCO})$, a proprioceptor that monitors upward and downward movements of the leg, was recorded in freely behaving crayfish, together with electromyograms from the levator muscle commanding this same joint. The orthodromic sensory action potentials as well as antidromic impulses conveyed in the sensory nerve were analyzed in relation to levator muscle activity. We report that in vivo, sensory coding by the CBCO appears much less specific than previously described in vitro (Le Ray et al. 1997a). In addition, we show that some antidromic action potentials in the CBCO nerve are generated exclusively during locomotion, whereas others may be linked to postural functions. Furthermore, our data suggest that antidromic discharges have an inhibitory effect on sensory coding associated with both locomotor and postural motor programs and that plasticity in both sensory coding and antidromic firing may occur as a function of the behavioral state of the sensory-motor apparatus. 


\section{MATERIALS AND METHODS}

\section{Experimental animals}

Experiments were performed on fifteen 12-15 cm-long crayfishes, Procambarus clarkii, maintained in an aquarium at $17-18^{\circ} \mathrm{C}$ and fed once a week. Animals were anesthetized on ice and remained immobilized during dissection and electrode placement. After surgery, they were kept in isolated compartments where they behaved freely while recordings were made over several consecutive days (up to 8 days).

\section{Innervation of the coxo-basipodite joint and disposition of recording electrodes}

The present work was done on the sensory-motor system of the second (coxobasipodite) joint of the fourth leg. The fourth leg was chosen because of its major role in walking (Jamon and Clarac 1995, 1997; Domenici et al. 1998). Leg levation is mainly controlled by the second proximal joint, the coxo-basipodite (CB) joint (Fig. 1A,B), which allows exclusively vertical movements of the basipodite (in the following, no distinction will be made between basipodite displacement and CB joint angular movement). The sensorymotor system of the $\mathrm{CB}$ joint consists of a proprioceptor, the chordotonal organ $\mathrm{CBCO}$ that monitors upward and downward movements of the leg, and a pair of antagonistic levator (Lev) and depressor (Dep) muscles that control, respectively, upward and downward movements of the leg. The choice of this sensory-motor system was also dictated by the large amount of anatomical and physiological knowledge accumulated from extensive in vitro studies. The organization of the sensory-motor innervation of the joint is particularly convenient since sensory and motor nerves originating from the central ganglion diverge proximally, allowing us to make differential recordings of sensory and motor discharge patterns. Moreover, the CBCO sensory nerve is long enough to allow the placement of two electrodes, permitting the discrimination of orthodromically and antidromically traveling action potentials.

The procedure used for chronic recording from nerves was adapted from the technique developed by Böhm (1996) for the crayfish stomatogastric nervous system. Four thin monopolar wires, traveling in a grounded cable fixed with wax on the back of the animals were used and, usually, three of them were attached to $50 \mu \mathrm{m}$ insulated wire electrodes to record muscular and nerves activity (see above), whereas a fourth electrode was placed under the carapace and used as a reference. Two wire electrodes were implanted through the cuticle and placed either both on the sensory nerve (7 experiments) innervating the CBCO (Fig. 1B- 
D) or one on the CBCO sensory nerve and the other on the anterior motor root (AMR) that includes $\mathrm{CBCO}$ axons prior to their entry into the ganglion (4 experiments). This latter recording configuration presented the advantage of increasing the distance between the recording electrodes to improve the precision of conduction velocity measurement, but also decreased the signal/noise ratio (in the AMR neurogram), which made identification of the CBCO units in the AMR more difficult (e.g., Fig. 9C). Impulses were accepted for analysis only when a constant shape was found in the AMR neurogram and a constant delay was found with a unit identified in the CBCO neurogram. Electrodes were isolated from the haemolymph with a flexible silicone elastomer (World Precision Instruments, FL; Fig. 1D). The third recording electrode was implanted directly into the anterior levator muscle through the cuticle and used to monitor muscle EMG activity (Fig. 1B) in order to monitor active movement of the CB joint (see Fig. 2 and methods below). Each recording electrode was fixed separately on the leg cuticle with wax before it reached its attachment to the grounded cable and connection to three homemade extracellular amplifiers. Amplified neurograms and EMG signals (e.g., Fig. 1G) were directed through a CED 1401 interface (Cambridge Electronic Design, UK) to a computer for storage and analysis.

In addition, in four other animals, the CBCO sensory nerve was cut distally, close to the proprioceptor, to avoid orthodromic sensory spikes. In this condition, only a single electrode was needed to record antidromic action potentials. Finally, in two animals the recorded leg was blocked temporarily in an elevated position by sticking the meropodite ( $4^{\text {th }}$ segment) against the thorax with wax, thereby maintaining the elastic strand of the $\mathrm{CBCO}$ in an almost completely released state. In both conditions, recordings of Lev EMG and CBCO nerve activity were performed during natural, free locomotor behaviors. Except in these last experimental conditions, animals performed normal displacements of the 4th leg during free walking. Especially, CB joint angular movements were not visibly perturbed and, although not measured during our experiments, they seemed to correspond to the standard angular ranges during locomotion (between about 15 and 40 degrees, 0 degree corresponding to the full levation, i.e. leg in contact with the thorax) reported previously (Jamon and Clarac 1997).

\section{Signal processing and data analysis}

Sensory neurograms were analyzed using the 'wave-marker' procedure of the Spike 2 program (CED). This procedure identifies most of the action potentials that are conveyed by a given nerve, according to their shape and amplitude, and groups similar action potentials into distinct classes. Each class was then considered as a unique $\mathrm{CBCO}$ unit (i.e., a single CBCO 
neuron). Thereafter, a homemade Spike 2 script program was used to compare the two recordings of the $\mathrm{CBCO}$ nerve. With this procedure, each impulse of a $\mathrm{CBCO}$ unit was used as a trigger to average (Fig. 1E) or superimpose (Fig. 1F) action potentials within the two neurograms in order to define the direction of their propagation and, thus, to identify sensory from antidromic units (although incorrect, the term of 'antidromic unit' is used in this report to describe a CBCO sensory neuron that also conveys antidromic action potentials). Because most action potentials were of small amplitude (especially several hours after the implantation of the electrodes) and could occur simultaneously in the neurograms, the shape of their average trace may appear deformed (e.g., Figs. 6 and 7). To eliminate identification problems, only the $\mathrm{CBCO}$ action potentials that were readily recorded with a constant delay between both electrodes were kept for subsequent analysis. For each spike shape recorded with an electrode, the occurrence (within a given time window) of a corresponding spike with a regular shape was sought in the recording from the other electrode. Although this procedure dramatically reduced the number of CBCO units considered in this study (and for each unit the number of orthodromic or antidromic action potentials, which consequently causes a strong underestimation of unit firing frequency), it also assured a reliable description of unit properties.

In some experiments, the angular movements of the $\mathrm{CB}$ joint were continuously monitored using a movement detector adapted from Marrelli and Hsiao (1976) and previously used to record swimmeret movements in lobster (Cattaert and Clarac 1983) and tailfan movements in rock lobster (Newland et al. 1992). This movement transducer is based on the propagation of electric fields in water. Two fixed electrodes are glued on the proximal edge of the $\mathrm{CB}$ joint and produce an electric field that is measured by a third electrode, which is glued to the distal edge of the $\mathrm{CB}$ joint and moves with the joint (Fig. 2A). This mobile electrode gives a linear measurement of the joint angle. The electric field is generated by a high frequency $(10-20 \mathrm{kHz})$ voltage instead of continuous current to avoid electrode polarization and measurement errors. Electrodes were made with silver wire, the tip of which was melted by flame in order to form a small silver sphere. This system has several advantages: (i) easy installation; (ii) reliability; and (iii) small size that does not perturb the movements of the animal. Nevertheless, when associated with the recording of nerve activity described above, this movement-recording apparatus considerably complicated the experiment and slightly altered the locomotor performance of the animal. For this reason therefore, we developed an alternative method to estimate the $\mathrm{CB}$ joint movements during free locomotion. A previous 
description by Jamon and Clarac (1997) in freely moving crayfish of the time course of the fourth leg movements prompted us to hypothesize that the EMG activity of the muscles controlling the $\mathrm{CB}$ joint, and especially the anterior levator muscle, could provide a good estimation of joint angular displacement. Given that EMG amplitude is considered to reflect to some extent the velocity of muscle contraction, EMG integral with a long time constant may then reflect the time course of the instantaneous limb position changes induced by muscle contraction. Therefore, in a series of experiments we analyzed the correlation between CB joint movements and integrals from Lev and Dep muscles EMGs. Figure 2B exemplifies such recordings in which a large variety of Lev and Dep EMG activities were produced during active movements of the $\mathrm{CB}$ joint $(C B M v t)$. In this example, after a series of irregular movements, the animal performed four walking steps (arrowheads in Fig. 2B and 2C), then stopped and produced complex movements of the leg (Fig. 2B). In the following analysis, only actual walking episodes were considered. Using a homemade Spike 2 script program, EMG recordings from Lev and Dep muscles were rectified and integrated using several integration times : $0.01 \mathrm{~s}, 0.05 \mathrm{~s}, 0.5$ and $1 \mathrm{~s}$. The actual angular movement of the CB joint was then correlated to both the Lev (Fig. 2C) and Dep (not shown since no clear correlation was found) integrals. This analysis demonstrated that the $\mathrm{t}=1 \mathrm{~s}$ integration of the Lev EMG (Fig. 2C) gives an excellent prediction of CB angular movements (compare the two last traces in Fig. 2C1), especially concerning the ascending phase of the leg movement (see details in Fig. 2D). This was confirmed by a linear regression analysis performed on the complete walking episode (Fig. 2E) which indicated that the relationship between integrated Lev EMG and angular position of the $\mathrm{CB}$ joint could be line fitted with a correlation coefficient of $\mathrm{r}=0.91$ (normalization of both the EMG integral and CB joint movement was performed because of the large difference between both sets of values). The slope of the curve was significantly different from $0 \quad(\mathrm{p}<0.0001)$. Similar observations were made from 5 experiments, which supported the hypothesis that Lev EMG integral could reflect reliably the angular displacements of the $\mathrm{CB}$ joint and, consequently, vertical movements of the leg. Hence, an integral positive slope indicated a rising leg movement, whereas a negative slope putatively corresponded to a leg downward movement. Of course, this method introduce a certain insensitivity in the detection of the movements used for latter analysis. For example, small amplitude movements may be produce while the EMG integration do not reflect them (e.g., Fig. 2B, movement trace between the two last arrowheads). However, in this report we focused on large steps during free walking without considering such small amplitude movements that were rather involved in posture correction. In addition, our analysis being 
performed on several walking steps and data thus representing an accumulation of spikes from identified $\mathrm{CBCO}$ units, taking into account such small amplitude movements would not modify sensibly the results. Therefore, to simplify the protocol and avoid implantation of too many wires when the CBCO neurograms were recorded, we used the integrated Lev EMG as an indicator of CB joint movements and the onset/offset of the Lev EMG as a reference for the analysis of CBCO neurons during walking (see Fig. 2F).

The activity of $\mathrm{CBCO}$ units were presented in raster displays using the onset/offset of levator EMG activity as a trigger. Also, for each CBCO sensory unit the spike occurrence was presented in event histogram (Figs. 3-5). Changes in the spike occurrence distribution, which define the most efficient joint position for each unit, were determined by means of the cumulative sum (Ellaway, 1978) of the changes in the bin count with respect to the mean count in a baseline (see also Mattei et al., 2003). The baseline was $1 \mathrm{~s}$ before either the onset (left part of panel A in Figs. 3-5) or the offset (right part of panel A in Figs. 3-5) of the Lev EMG burst. A similar analysis was performed on antidromic firing (Fig. 6 and 7), as well as on orthodromic-antidromic discharge correlations (Fig. 8). In the latter case, the baseline duration differed and is indicated in text and figure legends. A normalization procedure was applied in order to shift the curve toward only positive values to make data more visible (this did not affect the statistical analysis; see below). A curve of cumulative sum with a positive slope indicates that actual values are higher than the reference (i.e., indicates a higher firing probability), whereas a negative slope shows the opposite. A null slope shows no difference from the mean reference value (i.e., no change correlated to $\mathrm{CB}$ joint movement). A statistical test (Garnett \& Stephens, 1980) was used to determine any difference between spike occurrences in distinct parts of the histogram that were selected according to the changes in curve slope. Typically, statistical tests were performed between the baseline and four areas of the histograms (e.g., Fig. $2 \mathrm{~F}$ ): maximum slope at $\mathrm{t}=0$ to $0.4 \mathrm{~s}(\mathrm{t}=0$ being the trigger time reference) and each following second ( $\mathrm{t}=0$ to $1 \mathrm{~s}, 1$ to $2 \mathrm{~s}$, and 2 to $3 \mathrm{~s})$. These choices were made because: i) the initial $400 \mathrm{~ms}$ (after trigger) of the EMG integral corresponded to the maximum velocity of movement (steepest slope); ii) the position of the leg between 1 and $2 \mathrm{~s}$ corresponded to maximal up or down positions; and iii) the leg positions between $0-1 \mathrm{~s}$ and 2-3s were almost identical, and only the direction of the movement (upward or downward) differed. These procedures allowed us to clearly discriminate three classes of CBCO sensory neurons (Figs. 3-5) and different types of antidromic activity (Figs. 6 and 7). 


\section{RESULTS}

The CBCO nerve is purely sensory and contains the axons of 40 sensory neurons (see Cattaert and Le Ray 2001), with cell bodies located in the receptor organ itself (Fig. 1C). In the present study, results were obtained from 31 distinct locomotor episodes performed by 11 freely behaving intact crayfishes. Only clearly identified orthodromic spikes were considered to be generated by CBCO sensory units. This usually corresponded to a small number of unit profiles (with a mean number of 15 , over range from 3 to 28 ; $n=31$ recordings analyzed in intact animals). Similarly, few CBCO antidromic profiles were clearly identified in intact animals (from 0 to 8 , with a mean number of $2 ; n=31$ recordings). However, in certain conditions, for example with the CBCO nerve cut distally (see below), the number of identified antidromic profiles increased significantly up to 18 (with a mean number of $8 ; n=10$ recordings from 4 operated animals).

\section{Sensory coding in freely locomoting animals}

During free walking episodes, sensory units of the CBCO were analyzed according to the phase of movement (levation or depression, estimated with the Lev EMG integral; see methods) in which they were most active. Almost half of the identified sensory units were more active during the initial part of the Lev EMG burst and probably coded for upward movement or the elevated position of the leg, whereas only a few units showed a higher firing probability around the offset of the Lev EMG burst or between two consecutive bursts (Table 1). These latter units probably coded for downward movement and/or the depressed positions of the leg. Although every CBCO sensory neuron showed a specific pattern of discharge during free walking, it was possible to classify these activities (i.e., these coding properties) in three main groups according to the locomotor phase in which they were most active.

During locomotion, most of the identified CBCO sensory neurons showed a higher spike occurrence during the initial part of Lev EMG bursts (Fig. 3A left, and Table 1), which corresponded to the levation phase of a step, and a decreased spiking activity during the decaying part of the Lev EMG integral (Fig. 3A right). However, fine analysis revealed that they presented distinct peaks of activity, indicating specific sensitivities. Three types of sensory coding of levation are exemplified in Figure 3A. Some CBCO neurons showed increased firing during the whole Lev EMG burst (e.g. unit 1 in Fig. 3A top left) and a progressive reduction of spiking activity when the Lev EMG ceased (Fig. 3A top right). However, the majority of $\mathrm{CBCO}$ neurons fired preferentially during specific components of 
the EMG burst: neurons could have higher probabilities of firing that showed a symmetry related to the peak of the EMG integral (unit 2 in Fig. 3A middle left), which suggested a specific sensitivity to the elevated position of the leg rather than to movement velocity. This assumption is corroborated by the fact that no coding (i.e. no significant change in spike occurrence) was found at the end of and after the Lev EMG burst (Fig. 3A middle right). In contrast, other sensory neurons increased their firing only at the onset and during the first $100 \mathrm{~ms}$ of the Lev EMG burst during the maximum velocity phase (unit 3 in Fig. 3A bottom left) suggesting that they selectively sensed levation movement velocity rather than joint position (again, the absence of a change in activity at the end of the EMG burst corroborated this possibility; Fig. 3A bottom right). Considering the overall activity during walking, levation-sensitive $\mathrm{CBCO}$ units had a low mean firing frequency of $6.72 \pm 0.23 \mathrm{~Hz}$ (calculated from a sample of 26 identified units during eight walking episodes; e.g. Fig. 3B). However, single unit instantaneous frequency could reach very high values at the beginning of the levator muscle activity $(192 \pm 20 \mathrm{~Hz} ; \mathrm{n}=520$ action potentials from 26 identified neurons).

Besides levation-sensitive $\mathrm{CBCO}$ neurons, some sensory units were found to fire preferentially at the end of the Lev EMG burst or between two consecutive Lev EMG bursts (Table 1), i.e., when the leg depressed or was already in the down position (Fig. 4). As observed for the CBCO units coding for levation parameters, sensory neurons sensitive to leg depression also presented variable coding properties. Figure 4 illustrates two types of depression-sensitive CBCO neurons. Sensory unit 1 increased its firing around the trough of the Lev EMG integral (putative downward position; Fig. 4A top right), whereas it expressed no significant change in firing around the Lev EMG onset (Fig. 4A top left). Sensory unit 2 showed both a decreased firing during the initial part of the Lev EMG integral (i.e., leg levation; Fig. 4A bottom left) and an increased discharge when the Lev EMG integral decreased (i.e., probable leg depression to lowest position; Fig. 4A bottom right). In contrast to sensory unit 1 , sensory unit 2 did not seem to have a clear position sensitivity since no significant change of firing occurred in the latter part of the Lev EMG integral (between $t=2 \mathrm{~s}$ and 3s; see Fig. 4A bottom right) in which joint position was probably more or less the same as between $\mathrm{t}=1 \mathrm{~s}$ and $1.5 \mathrm{~s}$. However, because of the decrease of firing observed at the onset of the Lev EMG burst, sensory unit 2 neither can be considered as an unit coding exclusively for downward movement of the leg. In fact, no such purely depression-sensitive units could be highlighted in this work, and most $\mathrm{CBCO}$ neurons that were more active during this part of the locomotor cycle showed increased firing when Lev EMG integral decayed or between consecutive Lev EMG bursts (Table 1). So, for a given amplitude of Lev integral (i.e., a given 
position; see methods), the neuron had two distinct firing behaviors: an increased firing while the integral decayed (downward movement of the leg) and no change when integral increased (upward movement), perhaps therefore indicating a sensitivity to velocity in the downward direction. As described above for levation-sensitive sensory neurons, the latter, putatively depression-sensitive $\mathrm{CBCO}$ units fired during the whole locomotor cycle during free walking (Fig. 4B), from a low resting firing rate $(3.06 \pm 0.17 \mathrm{~Hz} ; \mathrm{n}=764)$ to an increased frequency of $150 \pm 84 \mathrm{~Hz}(\mathrm{n}=764)$ during their preferred phase of the locomotor cycle $(\mathrm{n}=20$ identified neurons during eight walking episodes).

Finally, during free walking episodes, a large majority of $\mathrm{CBCO}$ sensory neurons were found to produce a tonic discharge that never increased significantly (Fig. 5). In contrast, if any change was observed it consisted of a decrease in the occurrence of spikes at a given phase of the locomotor cycle. Indeed, most of these tonically active sensory neurons never showed any significant changes related to the locomotor cycle (unit 1 in Fig. 5A top), while other tonic sensory neurons exhibited a small but significant reduction in spike occurrence during rising (unit 2 in Fig. 5A middle) or falling (unit 3 in Fig. 5A bottom) phases of the Lev EMG integral (Table 1). Overall, tonic CBCO sensory units fired with a low frequency, ranging from 0.04 to $81 \mathrm{~Hz}$ during normal locomotor or postural activities (mean: $3.22 \pm 0.68 \mathrm{~Hz}$, calculated from a sample of 5,441 action potentials corresponding to 38 neurons identified during eight walking episodes; e.g., Fig. 5B).

Aside from the above classification only based on direction coding, the analysis of spike distribution histograms and cumulative sum curves highlighted that $\mathrm{CBCO}$ sensory neurons may present distinct movement-parameter sensitivities. Although the coding characteristics showed variation among the neurons, and it seemed that each neuron possessed its own properties, two types of firings showed clear increases in relation to Lev EMG activity, whereas another seemed to provide tonic information that might decrease during given phases of the locomotor cycle. Thus, some sensory neurons $(\sim 45 \%)$ specifically increased their firing probability in correlation to the steepest slopes of the Lev EMG integrals (e.g., Fig. 3A bottom), i.e. at the onset of the leg levation (positive integral slope) or putative depression (negative integral slope), which indicated a sensitivity specific to the velocity associated with either movement. Other CBCO sensory neurons ( 24\%) changed their firing probability without any clear peak of discharge at the onset or offset of Lev EMG (e.g., Fig. 4 bottom right), which could indicate a lower sensitivity to velocity and a higher sensitivity to position. 
Finally, about $31 \%$ of CBCO sensory neurons were characterized by a discharge that could not be clearly correlated to either part of the Lev EMG integral (e.g., Fig. 5 top).

\section{Antidromic action potentials}

In vitro, $\mathrm{CBCO}$ sensory neurons were found to propagate action potentials in both directions. While the aim of orthodromic action potentials is to convey sensory information, then antidromic spikes seem to exert an inhibitory effect on sensory activity (Bévengut et al., 1997). In the freely behaving crayfish, antidromic action potentials generated in the central nervous system and conveyed towards the peripheral sensory organ were recorded from the CBCO nerve during both walking and postural activities (see below). No antidromic activity was found that was specific to tail flips or defensive reactions (not illustrated; see Discussion). Therefore, we did not investigate further the two latter behaviors and focused our analysis on free walking episodes.

In the walking crayfish, antidromic action potentials are preferentially produced at the transition between levator and depressor EMG activity of each step. Figure 6 shows two examples of such antidromic activity that increased transiently $250-500 \mathrm{~ms}$ before the onset of the Lev EMG burst and then returned to control baseline (Fig. 6A left part; in Fig. 6, baseline was calculated between 1 and $0.7 \mathrm{~s}$ before trigger, and statistical tests were performed between baseline and every following 500ms). In contrast, these two antidromic activity patterns differed after Lev EMG offset (Fig. 6A right): although both showed a lower probability of occurrence within the 500ms that preceded the offset of the Lev EMG burst, only one neuron (unit 1 in Fig. 6A top right) increased its antidromic firing again in the following tens of milliseconds. This suggested that this latter neuron conveyed a second wave of antidromic action potentials at the beginning of depressor muscle activity.

Although the rate of both antidromic discharges was modulated during locomotion, they were also continuously expressed in the absence of locomotion (Fig. 6B) and at a very high frequency (up to $\sim 386 \mathrm{~Hz}$; mean: $48.7 \pm 1.0 \mathrm{~Hz}$, calculated from 5,278 action potentials cumulated from these two identified antidromic units). This demonstrated that antidromic activity in crayfish sensory neurons is not related uniquely to locomotor functions, despite previous in vitro experiments suggesting the contrary (see Cattaert and Le Ray 2001). Considering the overall activity during a single locomotor episode, no significant difference was observed in the mean firing frequency between the two antidromic discharges (AU 1: 48.0 $\pm 1.6 \mathrm{~Hz}$ and $\mathrm{AU} 2: 49.2 \pm 1.2 \mathrm{~Hz}$, for 3,090 and 2,188 action potentials, respectively). However, as suggested by the distribution histograms (Fig. 6A) the rate of antidromic 
discharges during walking differed from one neuron to the other (e.g., Fig. 6B): whereas the antidromic firing of AU 1 seemed to be little affected during locomotion, AU 2 was strongly depressed during free walking (note that in this figure, locomotor movements were mixed with complex Lev muscle contractions that did not alter the observed walking).

In intact animals, the number of distinct antidromic profiles clearly identified from the CBCO neurogram was always rather small (with a maximum of 8 distinct profiles of antidromic action potential). This might be due to the fact that the larger number of orthodromic (sensory) action potentials mask antidromic activity. We therefore recorded CBCO neurograms in animals $(n=4)$ with the $\mathrm{CBCO}$ sensory nerve cut close to the peripheral organ, and therefore in the absence of orthodromic activity. A larger number of antidromic units were now identifiable which were classified into two distinct groups. The first group occurred both during, and in the absence of motor activity (e.g., AU 1 in Fig. 7; see also Fig. 6 and text above), with an increased probability a few tens or hundreds of milliseconds before the onset of levator EMG activity (see Fig. 6). In contrast, the second group of antidromic units was found exclusively during motor episodes (AU 2 and AU 3 in Fig. 7A middle and bottom). Both AU 2 and AU 3 displayed a large increase in firing probability during the first $100 \mathrm{~ms}$ that followed the onset of levator EMG bursts, but only AU 3 maintained a higher level of discharge during the whole levator muscle burst (Fig 7A). In contrast, these two identified antidromic activities showed little or no discharge between successive locomotor cycles (Fig. 7B; in this figure, the locomotor episode occurred after a complex Lev EMG burst during which the animal changed its orientation before walking). Thus, this latter group may be defined as a mainly 'locomotor' antidromic group, whereas the first one may represent a 'postural' antidromic group (Table 2). Indeed, it is noticeable that the probability of firing 'postural' antidromic action potentials was strongly reduced during the first tens of milliseconds following the onset of levator EMG bursts during locomotor bouts (which corresponded to active movements; Fig. 7A top), whereas that of 'locomotor' antidromic action potentials was maximal (Fig. 7A middle and bottom). Overall, the mean frequency of 'locomotor' antidromic discharge was $1.11 \pm 0.17 \mathrm{~Hz}$ (calculated from 10,475 antidromic action potentials corresponding to 57 profiles identified from 25 locomotor episodes) whereas 'postural' antidromic discharges had a significantly higher $(\mathrm{p}<0.05)$ mean frequency of $2.07 \pm 0.40 \mathrm{~Hz}$ (calculated from 39,327 antidromic action potentials corresponding to 68 profiles identified from 25 locomotor episodes). Other than the higher mean number of antidromic profiles that were identified in the cut CBCO nerve $(6.8 \pm 1.4)$ compared to the intact $\mathrm{CBCO}$ nerve (3.6 \pm 0.7$)$, no qualitative differences were observed. The mean frequency 
of antidromic action potentials was not significantly different in intact and cut CBCO nerves (respectively $2.32 \pm 0.53 \mathrm{~Hz}$, for 18,107 action potentials from 44 profiles, and $1.24 \pm 0.22 \mathrm{~Hz}$, for 31,695 action potentials from 81 profiles). Moreover, 'locomotor' and 'postural' antidromic activities were identified in similar proportions ( $\sim 40 \%$ and $\sim 60 \%$, respectively) in the two experimental conditions.

\section{Inhibition of sensory coding by antidromic discharges}

Recent studies on in vitro crayfish (Bévengut et al. 1997; Cattaert and Bévengut 2002) and acute cat (Gossard et al. 1999) have suggested an inhibitory role for antidromic discharges in primary afferent sensory nerves. We assessed this possible function in the freely behaving crayfish by performing cross-correlations between sensory and putatively suppressive antidromic discharges (Fig. 8). Because it is impossible to associate individual antidromic and orthodromic spikes in vivo (due to dramatic differences in shape resulting from opposite directions of conduction), correlations were tested between every single CBCO orthodromic and antidromic discharge during all walking episodes. Figure 8 shows examples of successful cross-correlations, centered on the antidromic spikes $(t=0)$, with their curves of cumulative sum (in this case, control baseline was calculated between 1 and $0.1 \mathrm{~s}$ before the occurrence of the antidromic action potential, and statistical tests were performed on different time intervals following the antidromic spike). Two examples of such an analysis are presented in Fig. 8A and Fig. 8B: after the occurrence of antidromic spikes $(\mathrm{t}=0)$, the discharge of the corresponding orthodromic (sensory) unit was significantly decreased. This is indicated by the negative slope of the cumulative sum curve and was observed in all three classes of CBCO sensory neurons described above (i.e., in "velocity-" and "position-coding" neurons, and in tonically-active neurons). These results suggest that every CBCO sensory neuron may convey antidromic action potentials that would exert an inhibitory regulation on its sensory coding. Although inhibitory modulation of tonic sensory neurons was easier to detect, clear depression of the discharge of "velocity-sensitive" and "position-sensitive" sensory neurons could also be observed after antidromic action potentials (Fig. 8). Note that in some cases (e.g., Fig. 8B bottom) an increased orthodromic discharge could occur several hundreds of milliseconds (here, >500ms) after antidromic spikes. However, this increased sensory firing could result from either a property of the sensory neuron, similar to a postinhibitory rebound effect, or to the specific coding of an ongoing leg movement.

'Locomotor' antidromic discharges (indicated by '(L)' near t=0 in Fig. 8) only affected the firing of phasic sensory neurons (i.e., neurons probably coding for dynamic parameters of 
leg upward movement), and no suppressive effects could be found on tonic sensory neurons. In contrast, 'postural' antidromic discharges (indicated by '(P)' near $\mathrm{t}=0$ in Fig. 8) were found to depress the activity of all three classes of CBCO sensory neurons. These results suggest that "locomotor" antidromic discharges may exclusively be conveyed in "velocity-sensitive" sensory neurons, whereas any kind of $\mathrm{CBCO}$ sensory neurons may convey "postural" antidromic activities. However, the extracellular shapes of antidromic and orthodromic spikes are so different that such clear correlations would require further experiments using intracellular recordings from identified CBCO sensory neurons. Surprisingly, any inhibitory function could not found for a substantial proportion (about 50\%) of the antidromic activities identified from $\mathrm{CBCO}$ neurograms. In some cases, due to our experimental conditions this could result from a substantially too low basal discharge frequency of the sensory unit to show such modulation. In other cases, we cannot exclude the possibility that some of the identified antidromic action potentials were conveyed in the axon of sensory units that were not active in the angular range covered during free walking. When detected, depression of the sensory discharge lasted from 100ms (e.g., Fig. 8A bottom) to at least 1s (e.g., Fig. 8A middle) with a mean duration of inhibitory effect of $192 \pm 44 \mathrm{~ms}(\mathrm{n}=19$ correlations). Although it was impossible to test in our experimental conditions, the duration of the inhibitory effect might depend on the frequency of the antidromic discharge as previously suggested by in vitro experiments (Cattaert and Bévengut 2002).

\section{Plasticity of sensory coding and antidromic discharges}

Our in vivo experiments in which the CBCO nerve was cut distally suggested that the probability of firing of antidromic action potentials in sensory neurons might rely closely on the state of the proprioceptive apparatus itself. To investigate this possibility, recordings from the intact CBCO nerve were performed in two animals in control and after the fourth leg was blocked in a position where the CBCO strand was maintained in a released state (see methods). Both sensory and antidromic discharges were then analyzed without discrimination of walking from non-walking activities (e.g., Fig. 9). In the control condition, several orthodromic but no antidromic profiles were identified from the CBCO neurogram. In figure 9A, for example, 14 distinct orthodromic sensory units were identified within the three main classes defined above. After keeping the leg blocked for several days, several profiles of antidromic firing were detected, whereas the number of orthodromic units decreased dramatically. In fact, after five days none of the 14 orthodromic profiles that were detected in control conditions (Fig. 9A) were still encountered, but 12 distinct antidromic profiles were 
identified (Fig. 9B). So, when the leg was kept immobile the orthodromic/antidromic ratio of profiles (OAR) was inverted, suggesting that the direction in which action potentials are conveyed in $\mathrm{CBCO}$ sensory neurons is subject to plasticity according to the state of the biomechanical apparatus.

In another animal the time course of the OAR inversion was analyzed in three conditions in which the sensory feedback generated was different: during free walking episodes, in the absence of locomotion, and when the animal was held above ground and produced walking-like leg movements. In the latter condition the weight constraints and therefore a part of postural control were suppressed and therefore probably did not participate in the process of antidromic discharge generation. We found that whatever the behavioral context the OAR was subjected to similar changes (Fig. 9C). During free walking (§) in the control condition, a large majority of orthodromic units were detected (OAR=85.9\%). As soon as 30 minutes after the leg was immobilized, the OAR became inverted (OAR=37.6\%) and the number of identified antidromic profiles represented more than $50 \%$ of the profiles recorded from the CBCO/AMR neurograms (see methods). Thereafter, the OAR was calculated for two consecutive days in the three behavioral conditions. In all cases, the OAR decreased with time, due to both a reduced number of orthodromic units and an increase in the number of both 'locomotor' and 'postural' antidromic profiles. However, while OAR changes were similar in suspended $(\mathfrak{a})$ and freely walking animals (OAR=20\% and $17.1 \%$, respectively, after about $40 \mathrm{hr}$ ) it was noticeable that sensory activities disappeared only in the absence of locomotion (¥), suggesting that some sensory neurons might be directly sensitive to muscle contraction and remain excitable (see Discussion).

\section{DISCUSSION}

\section{In vivo sensory coding}

Based on correlations between neuronal discharge and Lev EMG activity, three classes of sensory neurons were distinguished in this study to be active during walking episodes. In contrast to earlier in vitro experiments (Le Ray et al. 1997a) identified sensory units were active in every phase of the locomotor cycle. For example, a CBCO sensory unit that fired during levator muscle activity also fired, albeit to a lesser extent, between consecutive levator EMG bursts and even in the absence of movement. Sinusoidal mechanical stimulation of the CBCO strand in vitro also caused some sensory units to fire during the full extent of the stimulation cycle. The main coding of these neurons therefore resulted from the sum vector of 
all single action potentials as determined from circular statistics (Le Ray et al. 1997a), and as also demonstrated more recently in humans (Roll et al. 2000). Although the irregularity of the locomotor cycle impedes such circular analysis, similar properties may also apply to in vivo sensory coding during free walking. Our present in vivo results show that most CBCO sensory neurons exhibit a low discharge rate throughout the locomotor cycle and, surprisingly, that the coding of a movement may reside in a decrease in neuronal discharge (e.g., Fig. 5A). Taken together with our earlier in vitro results, these data suggest that the $\mathrm{CBCO}$ monitoring of leg movements consists of a 'collegial' coding of the various biomechanical parameters of movements, and information consists of the "summation" of all the slight discharge changes that occur in the whole population of sensory neurons. This also suggests that small modifications in this sensory information, which will be integrated by motoneurons through many direct and polysynaptic connections (Le Ray et al. 1997a,b; Le Bon-Jego and Cattaert 2002; Le Bon-Jego et al. 2004), are sufficient to trigger adaptive locomotor responses. In fact, such a system would prevent sudden and abrupt motor responses that would invariably disturb equilibrium and result in locomotor deficiencies.

In insects, leg chordotonal organs are sensitive enough to detect very small vibrations (Stein \& Sauer 1999; Gopfert et al. 2002; Cokl and Virant-Doberlet 2003). Similarly, because of its location between the anterior and posterior levator muscles in the coxopodite (Cattaert and Le Ray 2001) the CBCO elastic strand may detect muscle contractions and relaxations that occur during all leg movements. In addition, leg movements may not be as regular as they seem to be and some up and down micro-movements of the joint may be encoded by the CBCO. This would explain why the CBCO sensory neurons that were found to be unidirectional in responsiveness in vitro (Cattaert and Le Ray 2001) seem to turn into bidirectional neurons in vivo. Thus, further investigation combining electroneurogram recordings and micro-movement analysis is required to fully understand the encoding properties of $\mathrm{CBCO}$ proprioceptive neurons in freely behaving crayfish.

\section{Antidromic activities in the freely behaving crayfish}

Antidromic discharges have been described in sensory nerves during central motor activity in both vertebrates (Dubuc et al. 1985, 1988; Gossard et al. 1989, 1991; Beloozerova and Rossignol 1999; Westberg et al. 2000) and invertebrates (Cattaert et al. 1992; Marchand and Leibrock 1994; Wildman and Cannone 1996; Marchand et al. 1997). They have been related to the locomotor CPG activity (Cattaert et al. 1992; Fellippa-Marques et al. 2000), as well as to sensory influences and descending commands (Vinay and Clarac 1999; for review, 
see Rudomin et al. 1993). Unlike these earlier in vitro studies, we show in the freely behaving crayfish that the $\mathrm{CBCO}$ sensory nerve always conveys antidromic action potentials toward the peripheral proprioceptor, whether the central nervous system is engaged in a walking activity or not. In vivo antidromic firing can be classified into two groups: the first group occurred either during or in the absence of walking and might be related to postural functions, whereas the second was specifically observed in locomoting animals and occurred mainly during walking leg movements. These latter antidromic action potentials occurred preferentially at the onset of levator EMG bursts (i.e., at the transition from depressor to levator motor commands) and might correspond to those described in the crayfish locomotor nervous system in vitro (see Cattaert et al. 2002). Although their occurrence probably depends largely on locomotor CPG activity, some 'locomotor' antidromic action potentials might also result directly from descending commands (see Vinay et al. 1999). In contrast, 'postural' antidromic discharges were observed during the whole locomotor cycle, although they also presented peaks of activity around the onset and the offset of Lev burst (i.e., probably during levation/depression transitions), and their origin remains unclear. Since they were never recorded from in vitro preparations that lacked both sensory and descending influences, one may exclude a CPG source and suggest an origin in either sensory feedback or descending commands, or both. Nevertheless, 'postural' antidromic spikes in vivo might also result from CPG activity induced by a specific neurohormonal environment that is removed in isolated preparations.

In this study, we analyzed the occurrence of antidromic CBCO spikes during different motor behaviors. Whereas some antidromic activity could be related to locomotion and posture, no antidromic action potentials were found to be specifically correlated to the defense reaction (i.e., when the crayfish faces a danger with its claws open) or escape behavior (tail flips). This is especially surprising since during tail flip a powerful depolarizing presynaptic inhibition of the CBCO sensory afferents is produced (El Manira and Clarac 1994), and therefore, antidromic spikes might also be expected to be generated (Cattaert et al. 2001). The absence of antidromic spikes associated with tail flips could result from our inability to extract them from the powerful sensory activity that also occurs during a tail flip or it might also result from synaptic mechanisms incompatible with antidromic spike generation (see Cattaert et al. 2001). However, the absence of antidromic discharge during specific locomotor functions may also reflect distinct levels of presynaptic control, as was recently demonstrated in the cat (Côté and Gossard 2003). 


\section{Modulation of CBCO sensory coding}

As suggested by in vitro analysis (Cattaert and Bévengut 2002), correlations between antidromic and orthodromic discharges during free walking indicated an inhibitory effect of the former on the sensory discharge of CBCO neurons of any type. Together with the fact that antidromic discharges are always present in intact animals, this latter negative correlation suggests that sensory coding is permanently regulated by antidromic activities. Consequently, the sensory coding that was analyzed in freely behaving intact animals in this study already reflected this regulation and, thus, did not correspond to the basic coding properties of the CBCO. Future comparison of sensory coding in intact CBCO nerve and proximally cut CBCO nerve, which would convey only orthodromic (sensory) action potentials, will be required to fully appreciate the extent of the inhibitory control exerted by antidromic discharges in freely behaving animals.

Antidromic spikes seem to depress a sensory discharge for several hundreds of milliseconds (see Fig. 8), which may be sufficient to filter specifically the sensory discharges associated with the dynamic component of leg movement (e.g., Fig. 3). Since the resistance reflex is mainly based on dynamic sensitivity (Le Ray et al. 1997b), the removal of movement-evoked sensory information would facilitate the expression of active movements. Indeed, preliminary experiments suggest that about $20 \%$ of the CBCO sensory neurons may lose their dynamic sensitivity during free walking when compared to imposed levation of the leg (unpublished observation). Although future experiments will be necessary to investigate this possibility further, these findings support our hypothesis that presynaptic inhibition, and thereafter antidromic discharges, are preferentially directed against the dynamic component of the resistance reflex (Le Ray et al. 1997a,b). Nevertheless, several sensory neurons may convey antidromic activity with distinct patterns of discharge during a given locomotor episode (e.g., Fig. 7), which suggests distinct levels of control exerted among the population of CBCO sensory neurons during locomotion. In addition, any negative correlation could be found for about half of the identified antidromically active units, either because the orthodromic firing rate of these neurons was too low or antidromic activity may support other possible functions.

\section{Plasticity of $C B C O$ nerve activity}

Our in vivo results indicate that the state of the proprioceptor may be a source of plasticity in $\mathrm{CBCO}$ nerve activity. In experiments in which the leg was constrained, sensory 
discharges slowly faded with time, and almost no coding persisted after several days. Nevertheless, some $\mathrm{CBCO}$ units that were active during locomotion remained active for longer than other sensory neurons. We hypothesize that, despite limb immobilization, the preservation of this specific coding was due to the continual activation of CBCO sensory units during limb muscle contraction. This suggests further that the long-term maintenance of CBCO coding properties is an activity-dependent phenomenon. Similar activity-dependence has already been described in vitro in the sensory terminal-to-motor neuron synapses that control the movement of the CB joint in crayfish (Le Ray and Cattaert 1999). Taken together, our data strongly suggest that the strength of the sensory-motor loop is highly dependent on the expression of recurrent locomotor movements.

Beside this state-dependence of sensory coding, a large increase in antidromic firing was observed in the CBCO nerve of immobilized legs. Previous experiments in crayfish in vitro (Cattaert and Bévengut 2002) and the acute cat (Gossard et al. 1999) suggested that the function of the antidromic action potentials is to reduce the sensitivity of the peripheral proprioceptor. Although our results obtained with blocked legs also support this hypothesis, the observation of antidromic spikes without clear inhibitory effects on any CBCO sensory neuron may suggest another role for the antidromic activity. Beloozerova and Rossignol (1999) reported that the number of antidromic action potentials recorded from cat dorsal root filaments increased after peripheral anesthesia or transection (i.e., in the absence of sensory activity in those filaments) and suggested that antidromic activity may create a link between central and peripheral processes. Taken together with our present results, we propose that antidromic discharges represent a form of central 'command' towards the peripheral proprioceptor to set its sensitivity into a dynamic range compatible with the state of both the locomotor nervous system and the sensory-motor apparatus.

\section{REFERENCES}

Beloozerova I, and Rossignol S. Antidromic discharges in dorsal roots of decerebrate cats. I. Studies at rest and during fictive locomotion. Brain Res 846: 87-105, 1999.

Bévengut M, Clarac F, and Cattaert D. Antidromic modulation of a proprioceptor sensory discharge in crayfish. J Neurophysiol 78: 1180-1183, 1997.

Böhm H. Activity of the stomatogastric system in free-moving crayfish (Orconectes limosus R.). Zoology 99: 247-257, 1996. 
Cattaert D, and Bévengut M. Effects of antidromic discharges in crayfish primary afferents. J Neurophysiol 88:1753-1765, 2002.

Cattaert D, and Clarac F. Influence of walking on swimmeret beating in the lobster Homarus gammarus. J Neurobiol 14: 421-439, 1983.

Cattaert D, El Manira A, and Bévengut M. Presynaptic inhibition and antidromic discharges in crayfish primary afferents. J Physiol (Paris) 93: 349-358, 1999.

Cattaert D, El Manira A, and Clarac F. Direct evidence for presynaptic inhibitory mechanisms in crayfish sensory afferents. J Neurophysiol 67: 610-624, 1992.

Cattaert D, and Le Ray D. Direct glutamate-mediated presynaptic inhibition of sensory afferents by the postsynaptic motor neurons. Eur J Neurosci 10: 3737-3746, 1998.

Cattaert D, and Le Ray D. Adaptive motor control in crayfish. Prog Neurobiol 63: 199-240, 2001.

Cattaert D, Libersat F, and El Manira A. Presynaptic inhibition and antidromic spikes in primary afferents of the crayfish: a computational and experimental analysis. $J$ Neurosci 21: 1007-1021, 2001.

Cokl A, and Virant-Doberlet M. Communication with substrate-borne signals in small plantdwelling insects. Annu Rev Entomol 48: 29-50, 2003.

Côté MP, and Gossard JP. Task-dependent presynaptic inhibition. J Neurosci 23: 1886-1893, 2003.

Duenas SH, Loeb GE, and Marks WB. Monosynaptic and dorsal root reflexes during locomotion in normal and thalamic cats. J Neurophysiol 63: 1467-1476, 1990.

Domenici P, Jamon M, and Clarac F. Curve walking in freely moving crayfish (Procambarus clarkii). J Exp Biol 201: 1315-1329, 1998.

Dubuc R, Cabelguen JM, and Rossignol S. Rhythmic antidromic discharges of single primary afferents recorded in cut dorsal root filament during locomotion in the cat. Brain Res 359: 375-378, 1985.

Dubuc R, Cabelguen JM, and Rossignol S. Rhythmic fluctuation of dorsal root potentials and antidromic discharges of primary afferents during fictive locomotion in the cat. $J$ Neurophysiol 60: 2014-2036, 1988.

Duysens J, Clarac F, and Cruse H. Load-regulating mechanisms in gait and posture: comparative aspects. Physiol Rev 80: 83-133, 2000.

El Manira A, and Clarac F. Presynaptic inhibition is mediated by histamine and GABA in the crustacean escape reaction. J Neurophysiol 71: 1088-1095, 1994. 
Ellaway PH. Cumulative sum tecnique and its application to the analysis of peristimulus time histograms. Electroencephalogr Clin Neurophysiol 45: 302-304, 1978.

Fellippa-Marques S, Vinay L, and Clarac F. Spontaneous and locomotor-related GABAergic input onto primary afferents in the neonatal rat. Eur J Neurosci 12: 155-164, 2000.

Garnett R, and Stephens JA. The reflex response of single motor units in human first dorsal interosseus muscle following cutaneous afferent stimulation. J Physiol 303: 351-364, 1980.

Gopfert MC, Stocker H, and Robert D. Atonal is required for exoskeletal joint formation in the Drosophila auditory system. Dev Dyn 225: 106-109, 2002.

Gossard JP, Bouyer L, and Rossignol S. The effects of antidromic discharges on orthodromic firing of primary afferents in the cat. Brain Res 825: 132-145, 1999.

Gossard JP, Cabelguen JM, Rossignol S. Intra-axonal recordings of cutaneous primary afferents during fictive locomotion in the cat. J Neurophysiol 62: 1177-1187, 1989.

Gossard JP, Cabelguen JM, and Rossignol S. An intracellular study of muscle primary afferents during fictive locomotion in the cat. J Neurophysiol 65: 914-926, 1991.

Hasan Z, and Stuart DG. Animal solutions to problems of movement control: The role of proprioceptors. Ann Rev Neurosci 11: 199-223, 1988.

Jamon M, and Clarac F. Locomotor patterns in freely moving crayfish (Procambarus clarkii). J Exp Biol 198: 683-700, 1995.

Jamon M, and Clarac F. Variability of leg kinematics in free-walking crayfish, Procambarus clarkii, and related inter-joint coordination. J Exp Biol 200: 1201-1213, 1997.

Le Ray D, and Cattaert D. Active motor neurons potentiate their own sensory inputs through retrograde glutamate-induced LTP. J Neurosci 19: 1473-1483, 1999.

Le Ray D, Clarac F, and Cattaert D. Functional analysis of the sensory motor pathway of resistance reflex in crayfish. I. Multisensory coding and motor neuron monosynaptic responses. J Neurophysiol 78: 3133-3143, 1997a.

Le Ray D, Clarac F, and Cattaert D. Functional analysis of the sensory motor pathway of resistance reflex in crayfish. II. Integration of sensory inputs in motor neurons. $J$ Neurophysiol 78: 3144-3153, 1997b.

Loeb GE. Hard lessons in motor control from the mammalian spinal cord. Trends Neurosci 10: 108-113, 1987.

Marchand AR, Barnes WJ, and Cattaert D. Primary afferent depolarization of sensory origin within contact-sensitive mechanoreceptive afferents of a crayfish leg. $J$ Neurophysiol 77: 3340-3354, 1997. 
Marchand AR, and Leibrock CS. Functional aspects of central electrical coupling in mechanoreceptor afferents of crayfish. Brain Res 667: 98-106, 1994.

Marrelli JD, and Hsiao HS. Miniature angle transducer for marine arthropods. Comp Biochem Physiol A 54: 121-123, 1976.

Mattei B, Schmied A, and Vedel JP. Recurrent inhibition of wrist extensor motoneurones: a single unit study in a deafferented patient. J Physiol (Lond) 549: 975-984, 2003.

McCrea DA. Spinal circuitry of sensorimotor control of locomotion. J Physiol 533: 41-50, 2001.

Newland PL, Cattaert D, Neil DM, and Clarac F. Steering reactions as adaptive components of the tail-flip in the spiny lobster Jasus lalandii. J Exp Biol 164: 261-282, 1992.

Roll JP, Bergenheim M, and Ribot-Ciscar E. Proprioceptive population coding of twodimensional limb movements in humans: II. Muscle-spindle feedback during "drawing-like" movements. Exp Brain Res 134: 311-321, 2000.

Rudomin P. Selectivity of the central control of sensory information in the mammalian spinal cord. Adv Exp Med Biol 508: 157-170, 2002.

Rudomin P, Quevedo J, and Eguibar JR. Presynaptic modulation of spinal reflexes. Curr Opin Neurobiol 3: 997-1004, 1993.

Sillar KT, and Skorupski P. Central input to primary afferent neurons in crayfish, Pacifastacus leniusculus, is correlated with rhythmic motor output of the thoracic ganglia. J Neurophysiol 55: 678-688, 1986.

Slesinger P, and Bell CC. Primary afferent fibers conduct impulses in both directions under physiological stimulus conditions. J Comp Physiol 157: 15-22, 1985.

Stein W, and Sauer AE. Physiology of vibration-sensitive afferents in the femoral chordotonal organ of the stick insect. J Comp Physiol 184: 253-263, 1999.

Vinay L, Brocard F, Fellippa-Marques S, and Clarac F. Antidromic discharges of dorsal root afferents in the neonatal rat. J Physiol (Paris) 93: 359-367, 1999.

Vinay L, and Clarac F. Antidromic discharges of dorsal root afferents and inhibition of the lumbar monosynaptic reflex in the neonatal rat. Neuroscience 90: 165-176, 1999.

Westberg KG, Kolta A, Clavelou P, Sandström G, and Lund J. Evidence for functional compartmentalization of trigeminal muscle spindle afferents during fictive mastication in the rabbit. Eur J Neurosci 12: 1145-1154, 2000.

Wildman M, and Cannone A. Sensory feedback and central afferent interaction in the muscle receptor organ of the crab, Carcinus maenas. J Neurophysiol 76: 788-798, 1996. 


\section{LEGENDS}

Figure 1: Sensory neurogram recordings in the freely behaving crayfish. A: Drawing of a crayfish $4^{\text {th }}$ leg showing the CBCO location. B: Detail showing the anatomical organization of the muscles that control the first (Pro: protractor; Rem: remotor) and the second leg joints (Lev: levator; Dep: depressor) together with the proprioceptor CBCO and its sensory nerve (CBCOn). Electromyogram and electroneurogram recording electrodes are also indicated. C-D: Usually two chronic isolated electrodes were used to record the $\mathrm{CBCO}$ action potentials. E-F: Spikes found in both $\mathrm{CBCO}$ neurograms were averaged (E) and superimposed (F) for discrimination of orthodromic from antidromic $\mathrm{CBCO}$ action potentials. G: During in vivo experiments, the EMG activity of the levator muscle was recorded and integrated (Integ. Lev EMG) together with the CBCO neurograms.

Figure 2 : Lev EMG activity and CB joint movements used for CBCO spiking analysis. A: System used to record the angular position and movements of the coxo-basipodite joint. The two open circles on the coxopodite represent the silver balls used to generate the electrical field (dashed lines). The open circle on the basipodite represents the silver electrode used to measure the electric field and, thereby, the angle of the joint. B: Lev and Dep EMG recordings and integrals (with 1s integration time; Lev Integ and Dep Integ) during active movements of the $\mathrm{CB}$ joint (CB Mvt). The direction of movements are indicated by arrows. Arrowheads above movement trace indicate locomotion cycles. C-E: Correlation of Lev EMG 1s-integral with CB joint movements during walking. Expanded time base (D) shows clear similarities between the Lev EMG integral and CB ascending movement phases. Correlation analysis between normalized Lev EMG integral and CB movement also gives a high coefficient of correlation with a very low $\mathrm{p}$ value throughout the locomotor episode $(\mathrm{E})$. F: Analysis of neuron discharge during free walking. In this example, the onset of the Lev EMG burst was used to trigger the event histogram of the CBCO sensory unit discharge. A cumulative sum curve, which highlights changes in occurrence probability, was built from the event histogram and statistical tests were performed between the basal discharge (calculated during 1s before the Lev EMG onset; horizontal black bar on the event histogram) and several post-trigger time intervals (vertical, doted lines). Black parts of the curve show significant differences with baseline, and stars indicate the level of significance. Raster of CBCO unit spiking is displayed at top of the figure, and the mean EMG integral is positioned above the mean EMG activity. Following figures will be constructed with the same organization with both the onset and the offset of the Lev EMG used as trigger. 
Figure 3: Sensory units coding for leg levation movements during free walking. A: Raster, event histograms and cumulative sum curves of the spiking activity of three different $\mathrm{CBCO}$ sensory neurons during 18 walking steps, with the onset ( $\mathrm{t}=0$ on left panel) and the offset ( $\mathrm{t}=0$ on right panel) of the Lev EMG used as the event trigger. The specific time points used as intervals for statistical calculations are indicated on the $\mathrm{X}$-axis of histograms (1 to 0 s for baseline, $0-0.4,0-1,1-2$, and 2-3s). Distinctly different sensitivities of the three units are illustrated: unit 1 codes for both positional and dynamic parameters, whereas unit 2 codes only for position and unit 3 for velocity. The shape of the corresponding action potentials on both $\mathrm{CBCO}$ recording electrodes is illustrated by the average traces between left and right panels. *: $\mathrm{p}<0.05 ; * *: \mathrm{p}<0.01 ; * * *: \mathrm{p}<0.001 \mathrm{~B}$ : Instantaneous firing frequency of the three same CBCO sensory units during a locomotor episode (represents a part of the total locomotor episode used to generate raster and event histograms in $\mathbf{A}$ ).

Figure 4: Sensory units putatively coding for leg depression movements during free walking. Same organization as in Figure 3, with two CBCO sensory units showing positional (unit 1) and dynamic (unit 2) responsiveness. Same experiment as in Figure 3.

Figure 5: Tonic sensory units during free walking. Same organization as in Figure 3, showing three tonically active CBCO units. Whereas unit 1 is unaffected by free walking movements, the discharge of unit 2 and unit 3 is depressed during upward and downward movements, respectively. Same experiment as in Figure 3.

Figure 6: In vivo antidromic discharges in the intact $\mathrm{CBCO}$ nerve during free walking. Same organization as in Figure 3. Analysis performed on 23 walking steps. The specific time points used as intervals for statistical calculations are indicated below the histograms ( -1 to $0.7 \mathrm{~s}$ for baseline, -0.5 to $0,0-0.5$, and $0.5-1 \mathrm{~s}$ ). Although both units displayed antidromic spiking activity before the onset of the levator EMG burst and were depressed just after, only unit 1 also increased its discharge some 500ms after the offset of the EMG burst (A). Moreover, their discharges were differently affected during motor activity (B). In this motor sequence, walking-associated Lev EMG bursts (arrowheads) were altered by complex EMG activities. However, these latter activities did not interfere visibly with walking. *: $p<0.05$; $* *: \mathrm{p}<0.01$. 
Figure 7: In vivo antidromic discharges in the distally cut $\mathrm{CBCO}$ nerve during free walking. A: The levator EMG onset (43 walking steps) was use to trigger event histograms for three distinct identified antidromic units that are presented as superimposed action potentials on the right. One antidromic unit (AU 1) showed a dramatically decreased discharge at the onset of levator activity, whereas two other units (AU 2 and AU 3) showed a large increase in activity at the onset of levator EMG bursts. B: Locomotor episode showing the occurrence of the three identified antidromic activities, with AU 1 discharging preferentially in the absence of motor activity and AU 2 and AU 3 exclusively active when the animal moved. In this sequence, walking-associated Lev activities (arrowheads) were preceded by a change of body orientation which resulted from fast, small amplitude leg displacements (below horizontal bar).

Figure 8: In vivo inhibitory effects of antidromic discharges on orthodromic CBCO sensory coding during free walking. A-B: Cross-correlations showing that the discharge of the three types of CBCO sensory neuron (tonic, "velocity-" or "position-sensitive" neuron) are depressed for several tens or hundreds of milliseconds after the occurrence $(t=0)$ of antidromic action potentials. The type of antidromic activity is indicated in brackets near $\mathrm{t}=0$ : $\mathrm{P}$, postural; L, locomotor. The specific time points used as time intervals for statistical calculations are indicated below lower histograms ( -1 to -0.1 s for baseline, 0 to $0.1,0.2,0.4$ or 0.5 , and 0.5 1s). A and B: two different animals. *: $\mathrm{p}<0.05 ; * *: \mathrm{p}<0.01 ; * * *: \mathrm{p}<0.001$.

Figure 9: Behavioral plasticity of sensory and antidromic activities recorded in vivo from the CBCO nerve during free walking. A-B: In a crayfish with the $4^{\text {th }}$ leg free, 14 orthodromic sensory units were identified (A), whereas after five days of leg restraint in levated position no sensory coding persisted but 12 antidromic profiles appeared (B). In this study, no distinction was made between Lev EMG activities associated or not with walking (arrowheads). C: Changes in the ratio of identified orthodromic (empty bars) and antidromic units (filled bars) in control and in three conditions at various times after the leg had been immobilized in the up position. $\S$ : during free locomotion; $\mathfrak{x}$ : when the animal was held above the ground; $¥$ : in the absence of locomotion. Averaged action potentials on the right part of the figure exemplify orthodromic (OU) and antidromic units (AU) recorded from both the $\mathrm{CBCO}$ nerve $(\mathrm{CBn})$ and the anterior motor root (AMR).

Table 1: Summary of sensory CBCO units identified from 11 freely behaving animals. Total number of units in either levation- or putatively depression-sensitive groups and in tonic 
neurons, as well as the mean percentage of these units compared to the total number of sensory neurons identified. Similar proportions where found in single animals. For non tonic neurons, a classification in probable "movement" and "position" sensitivity is given, as well as for tonic neurons the locomotor phase that cause a decrease in their firing.

Table 2: Summary of antidromic discharges analyzed in 11 freely behaving animals. Same organization as Table 1, with the locomotor phase associated with the peak of 'locomotor' antidromic discharge and the major decrease of 'postural' antidromic activity given. 
Figure 1

A

B

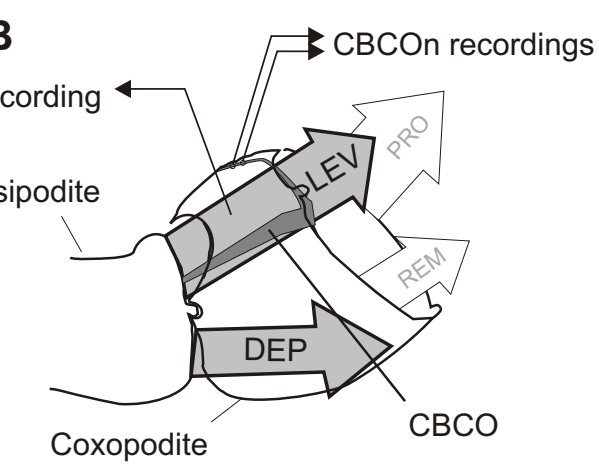

C

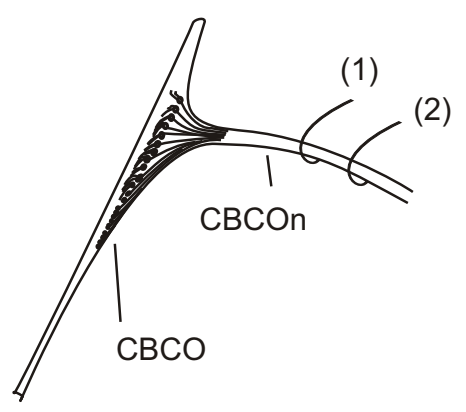

D

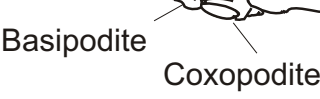

CBCOn recording
electrodes

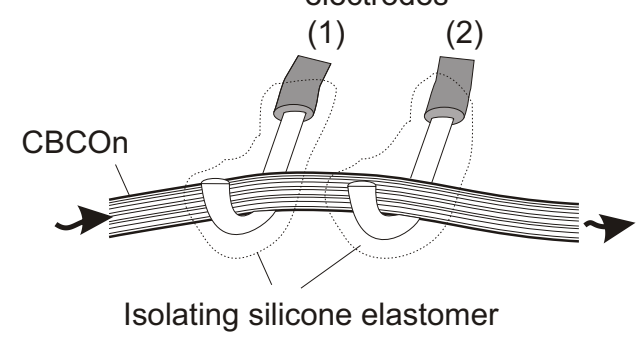

E

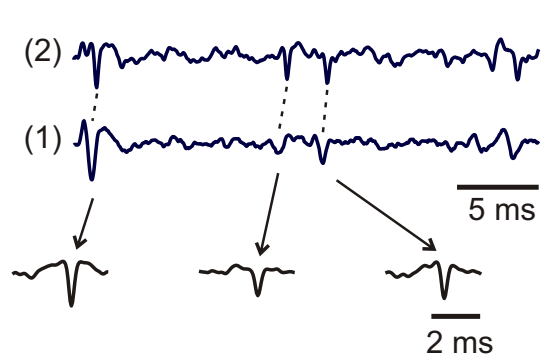

$\mathbf{F}$

Orthodromic unit Antidromic unit

G

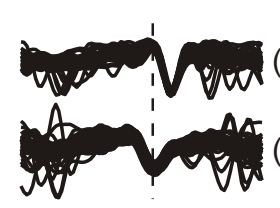

(2)

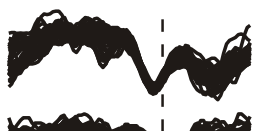

(1)

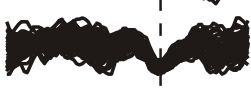

CBCOn

(2)

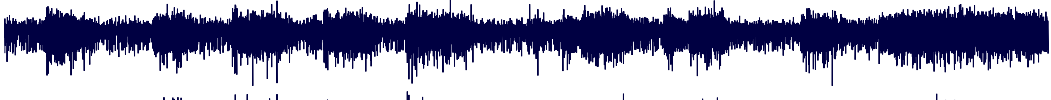

(1)
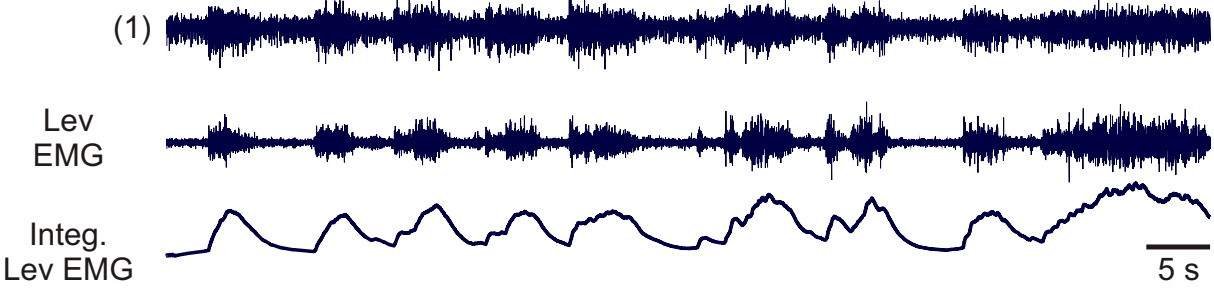
Le Ray et al, 2004

Figure 2

A

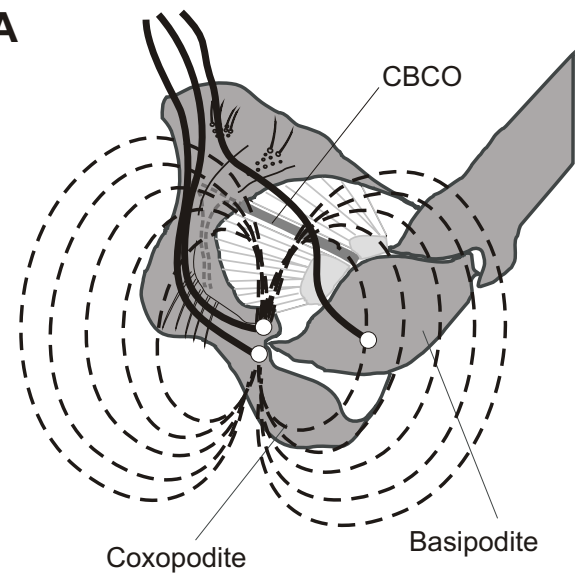

C

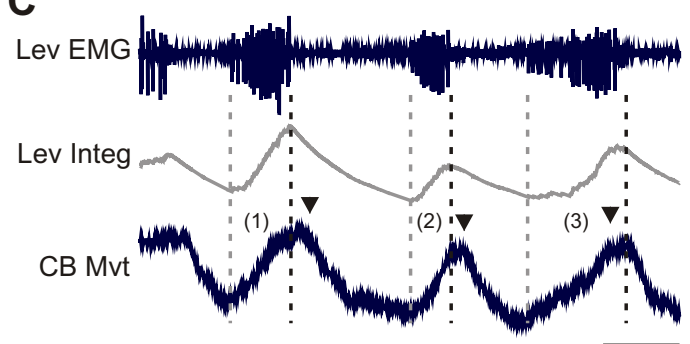

D

(1)

(3)

(1) "

(2)

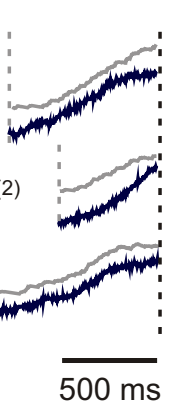

E

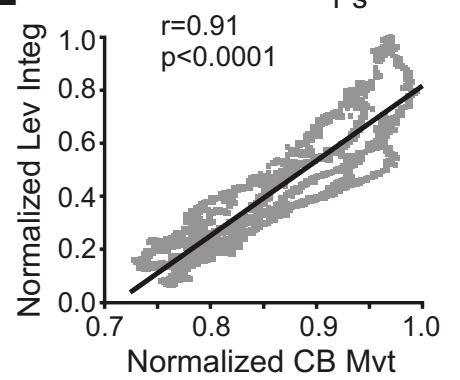

B

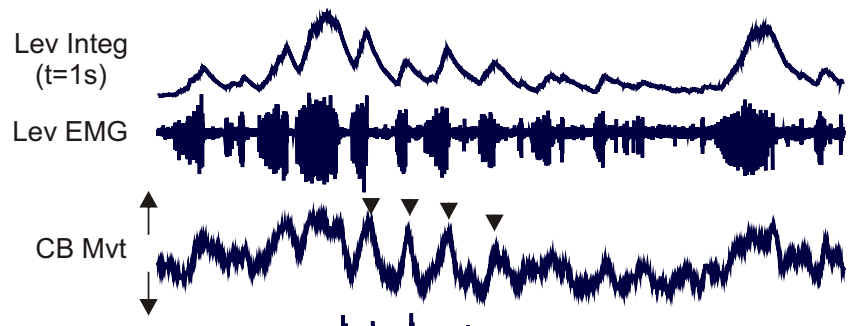

Dep EMG

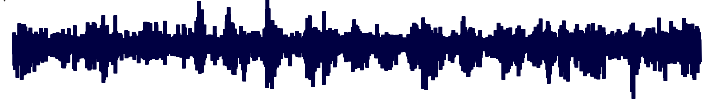

Dep Integ

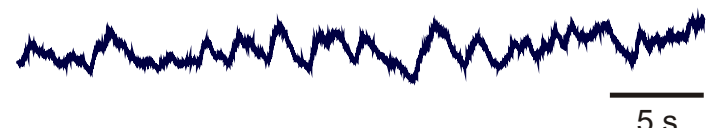

$\mathbf{F}_{\mathrm{CBCO}}$

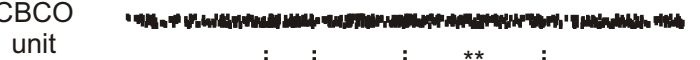

Mean Lev

EMG Integral

Mean Lev

EMG activity

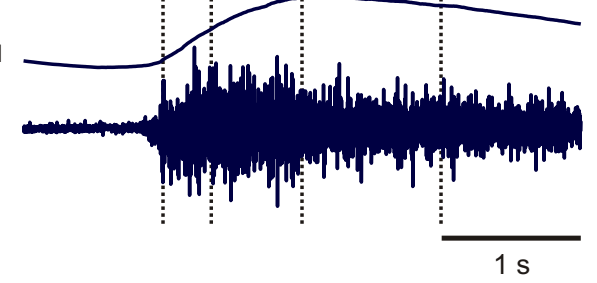


Le Ray et al, 2004

Figure 3

A
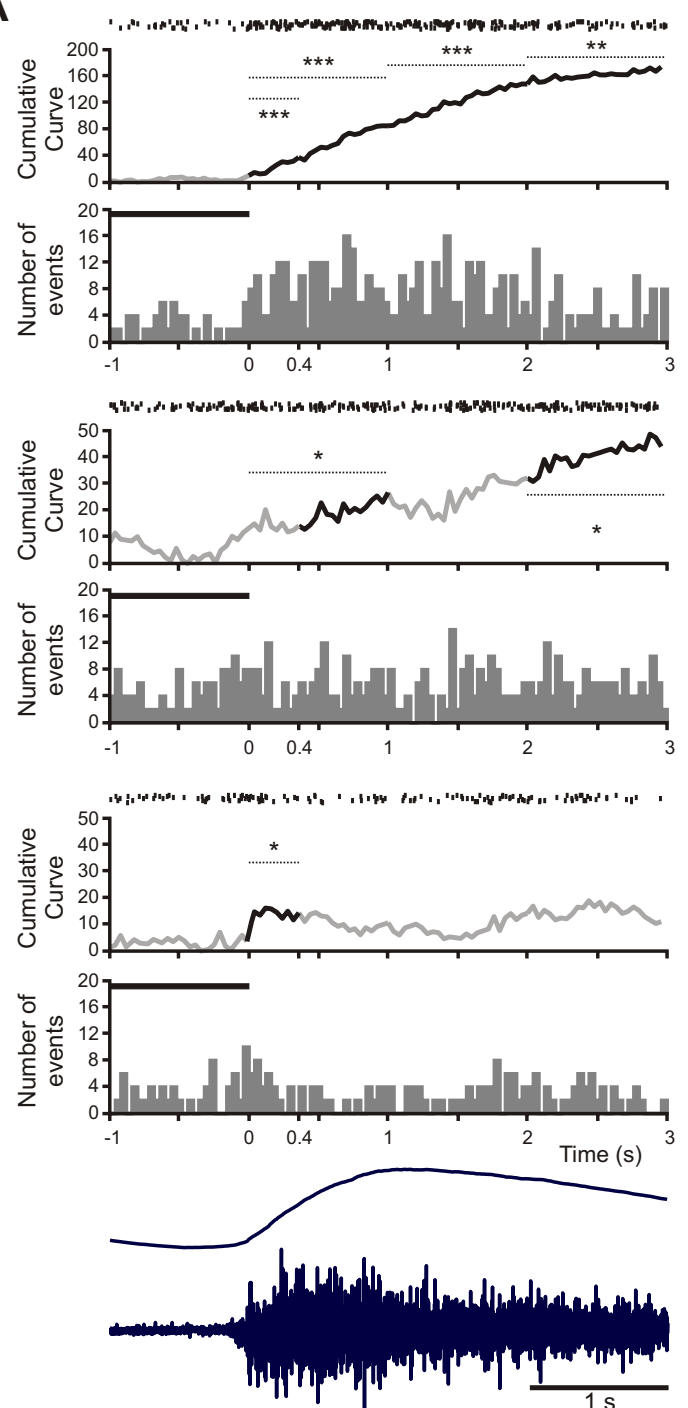

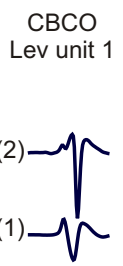

CBCO Lev unit 2

(2) $\sim$

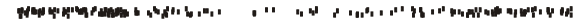

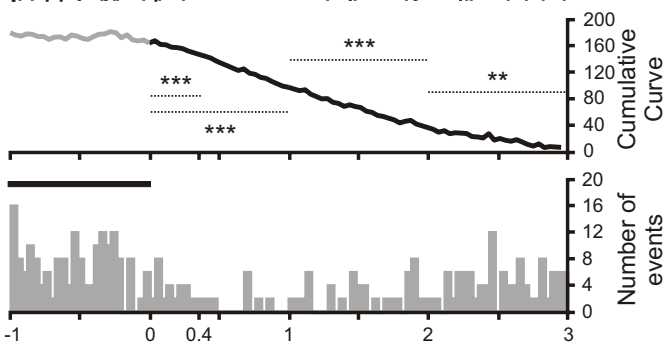

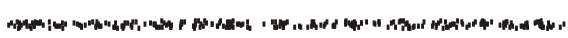

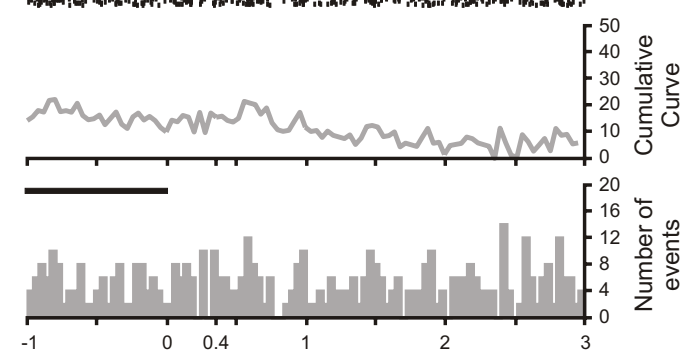

CBCO
Lev unit3

(1)

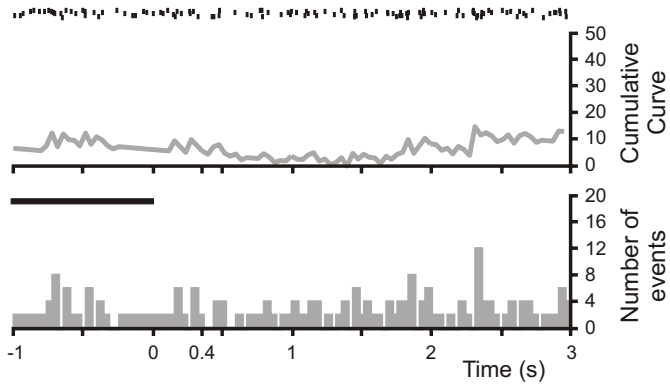

Mean Lev EMG Integra

Mean Lev EMG activity

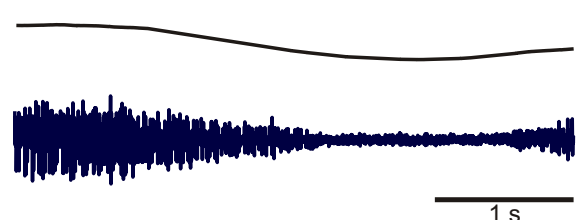

B

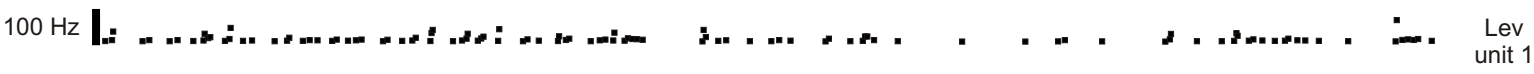

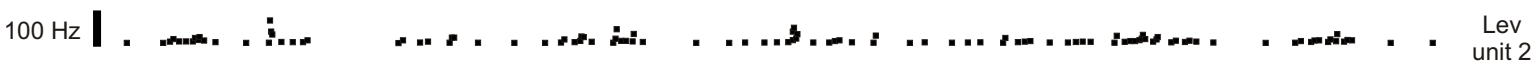

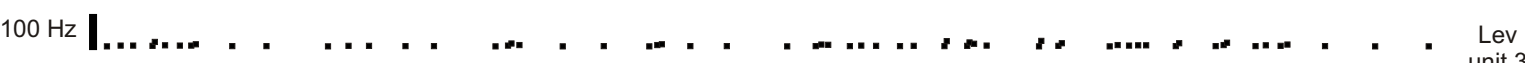

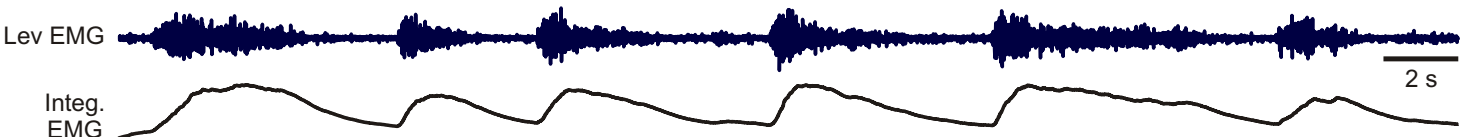
EMG 


\section{Le Ray et al, 2004}

Figure 4

A
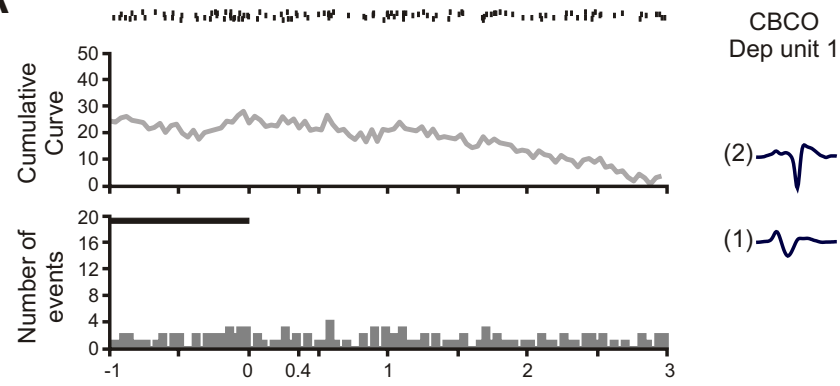

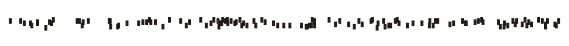

Dep unit 1

$(2)-\sqrt{2}$

(1) $\sqrt{ }$
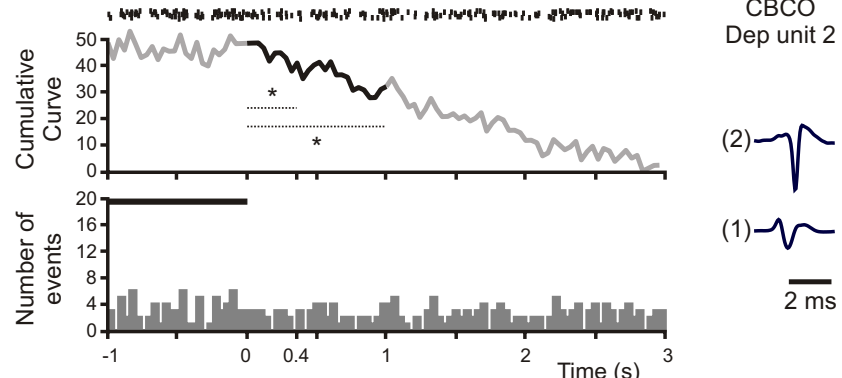

(1) $\sqrt{ }$

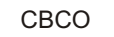

Dep unit 2

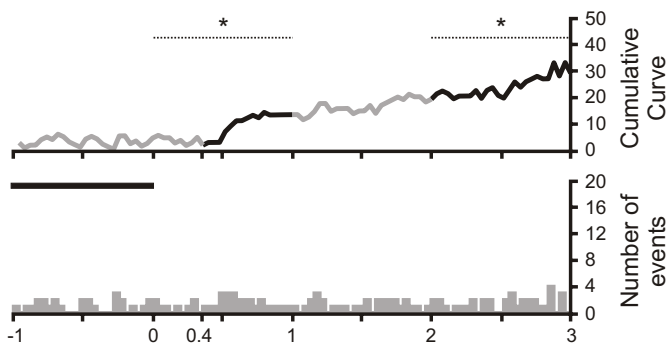

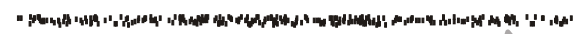

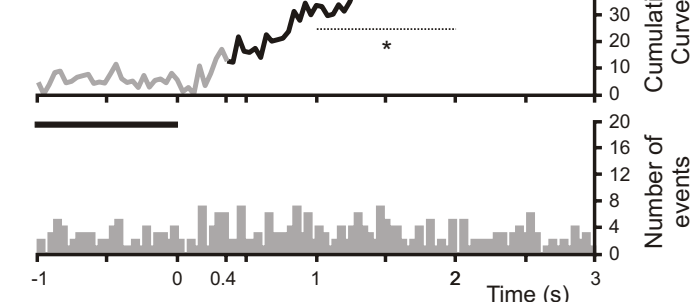

B

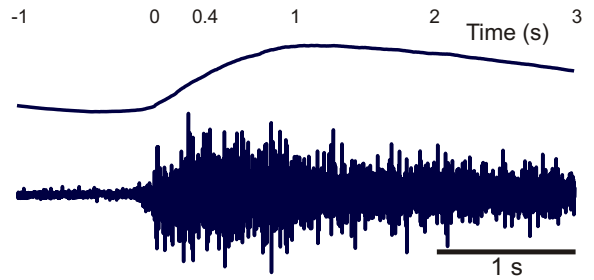

Mean Lev EMG Integral

Mean Lev EMG activity
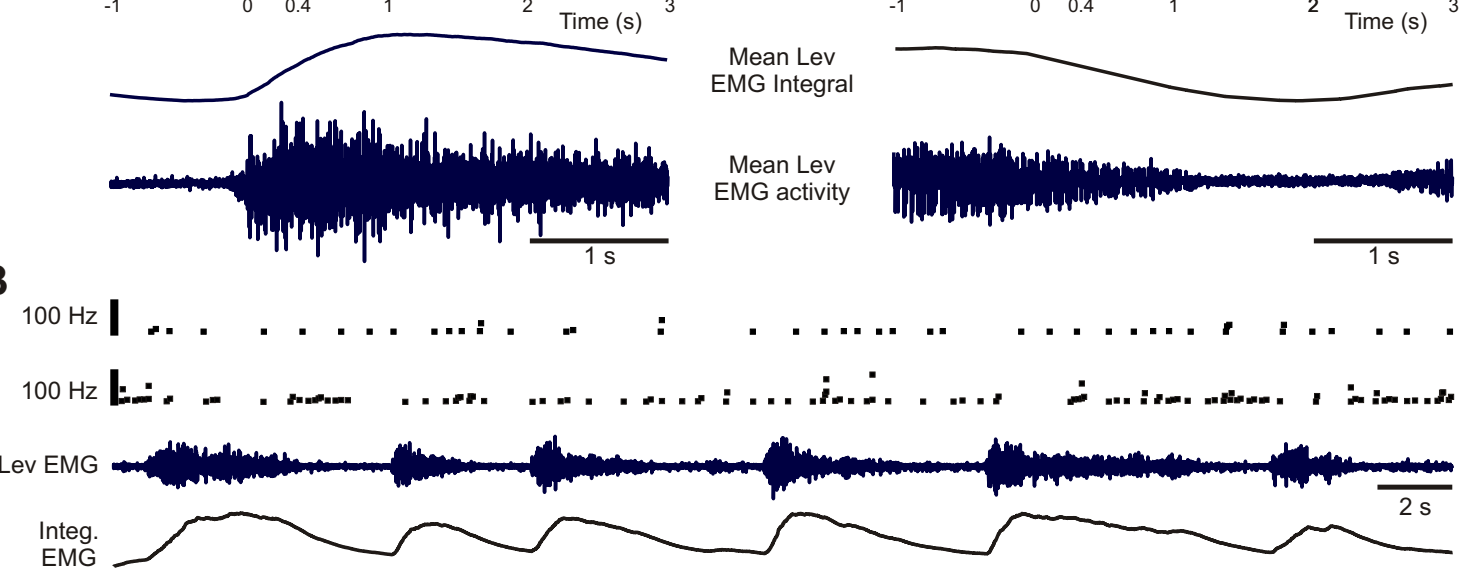
Le Ray et al, 2004

Figure 5

A
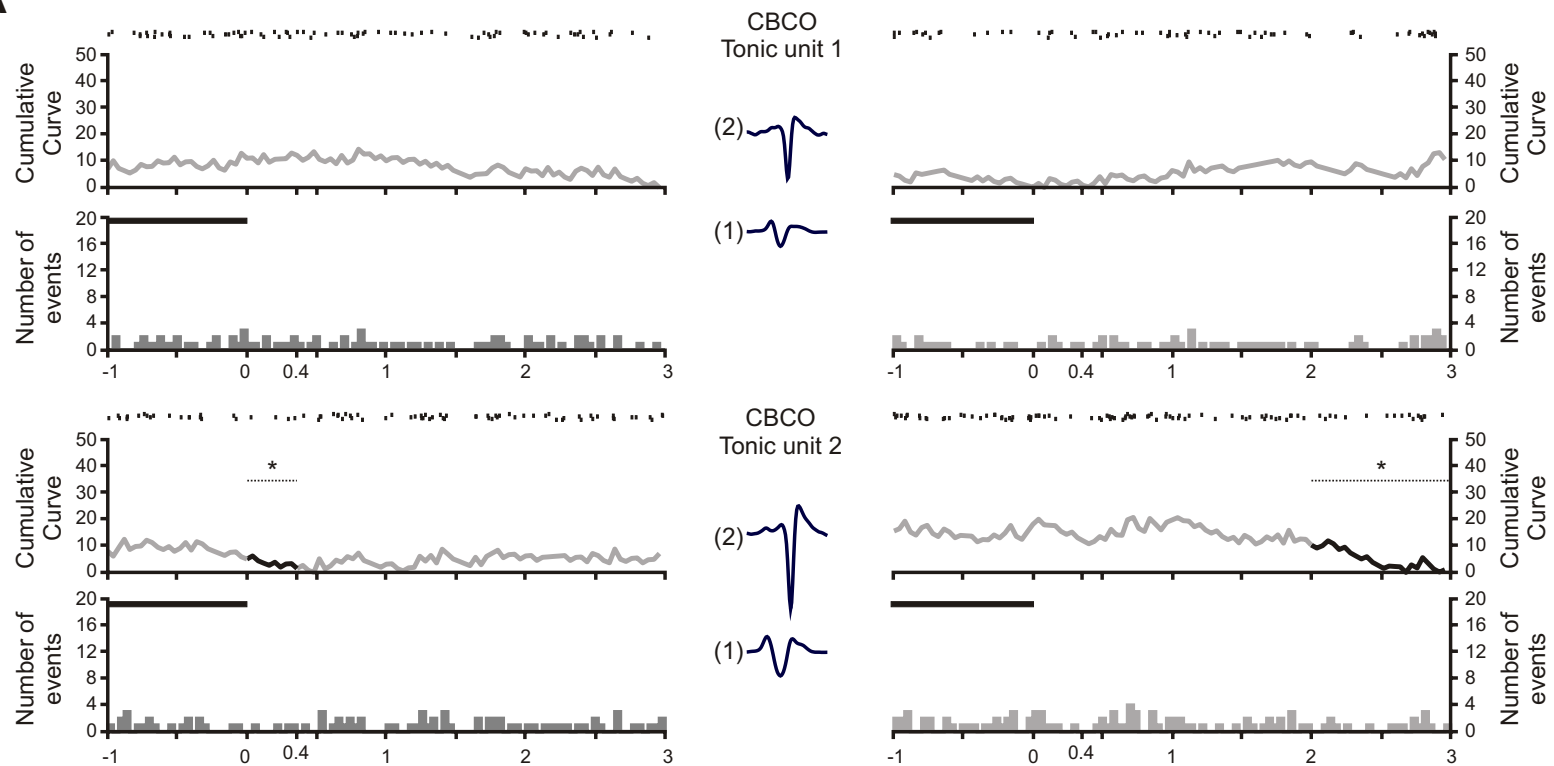

Tonic unit 2
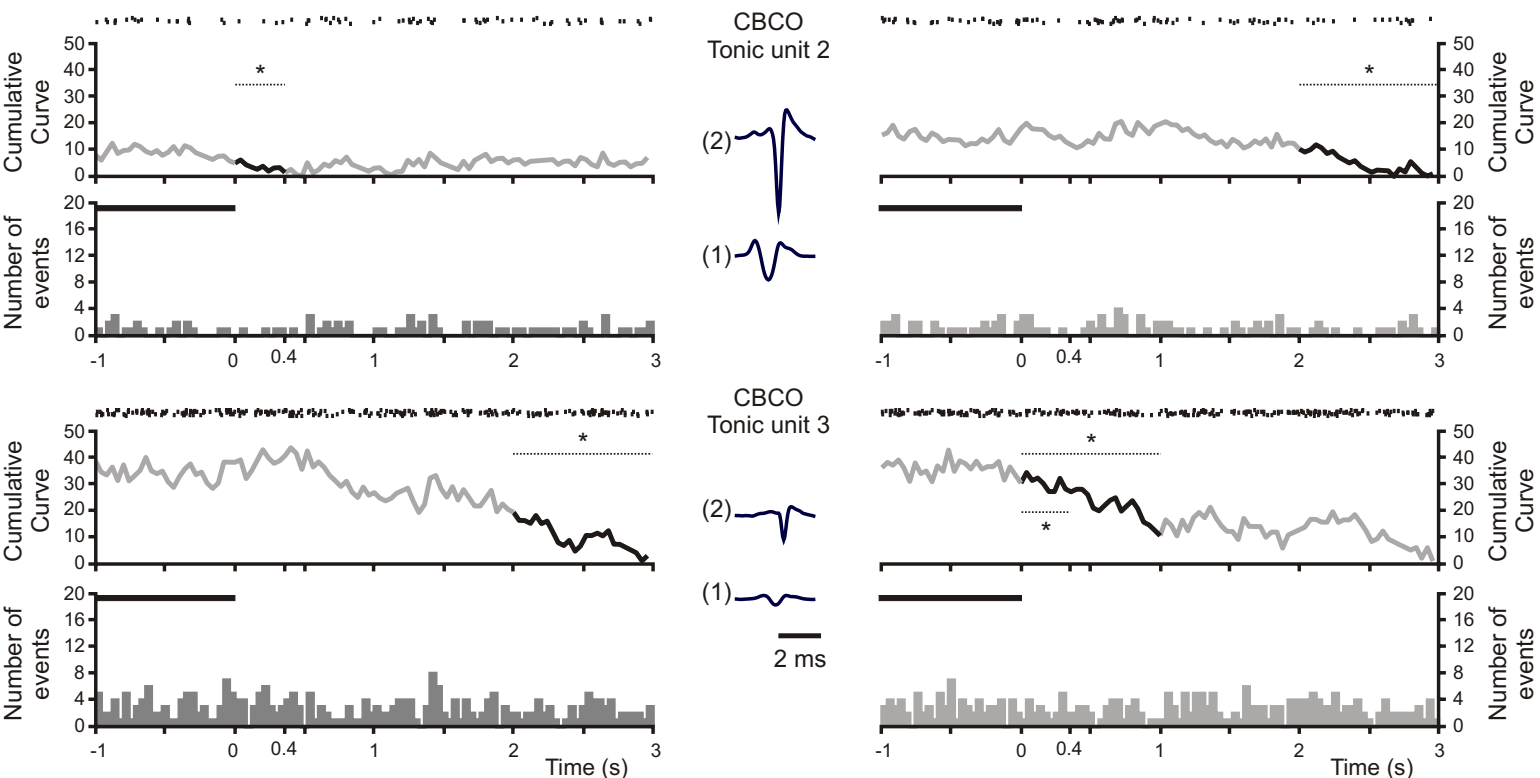

(1) 1

$\frac{\infty}{2}$

CBCO

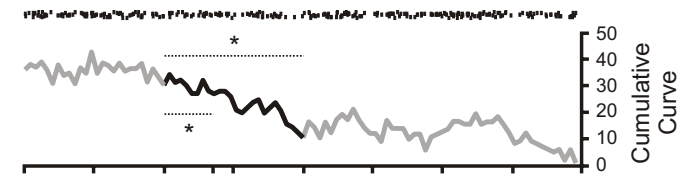

(2)

(1)

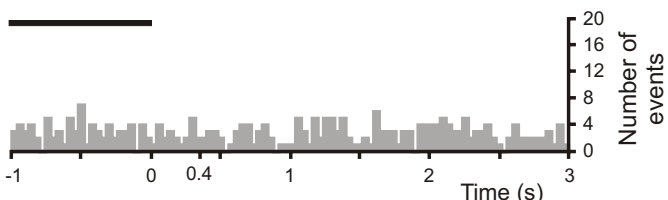

Mean Lev EMG Integral

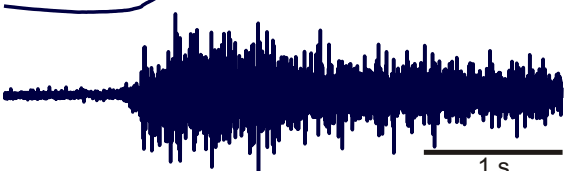

Mean Lev EMG activity

B
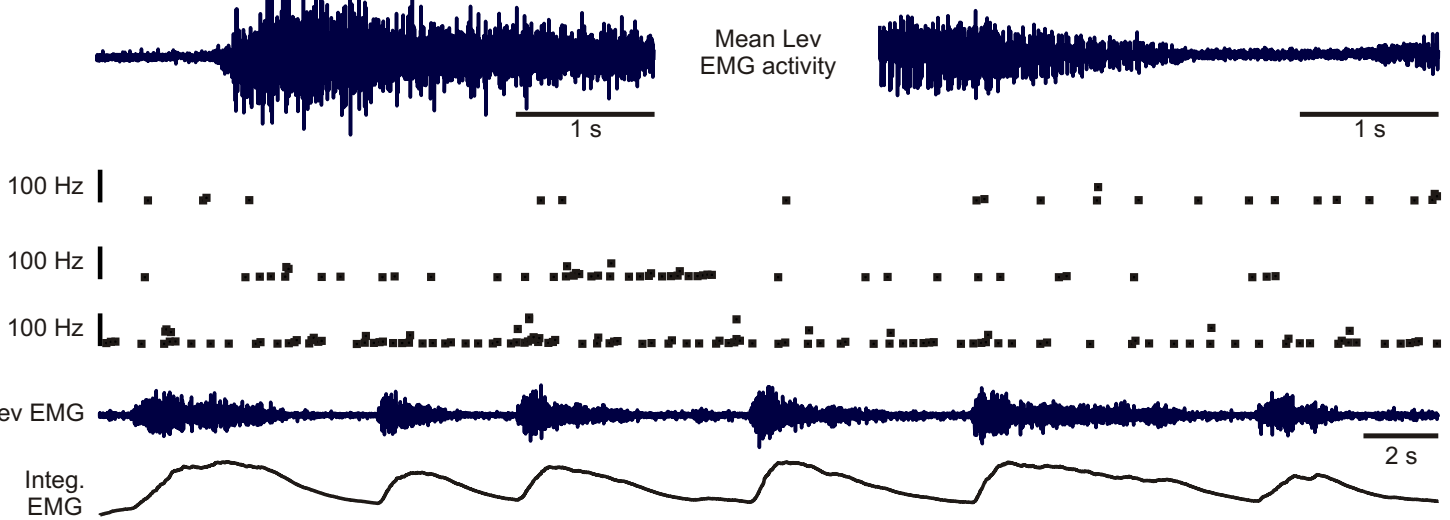


\section{Le Ray et al, 2004}

Figure 6

A
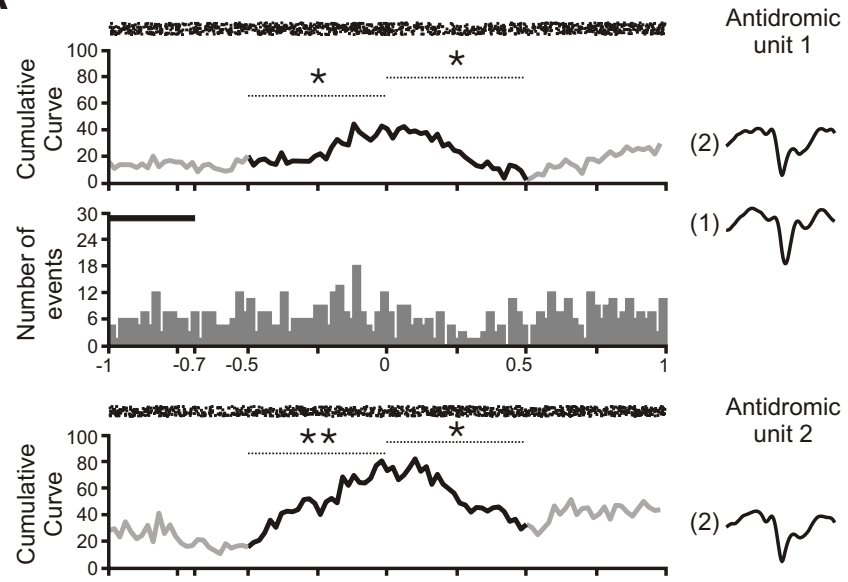

Antidromic unit 2

ANA
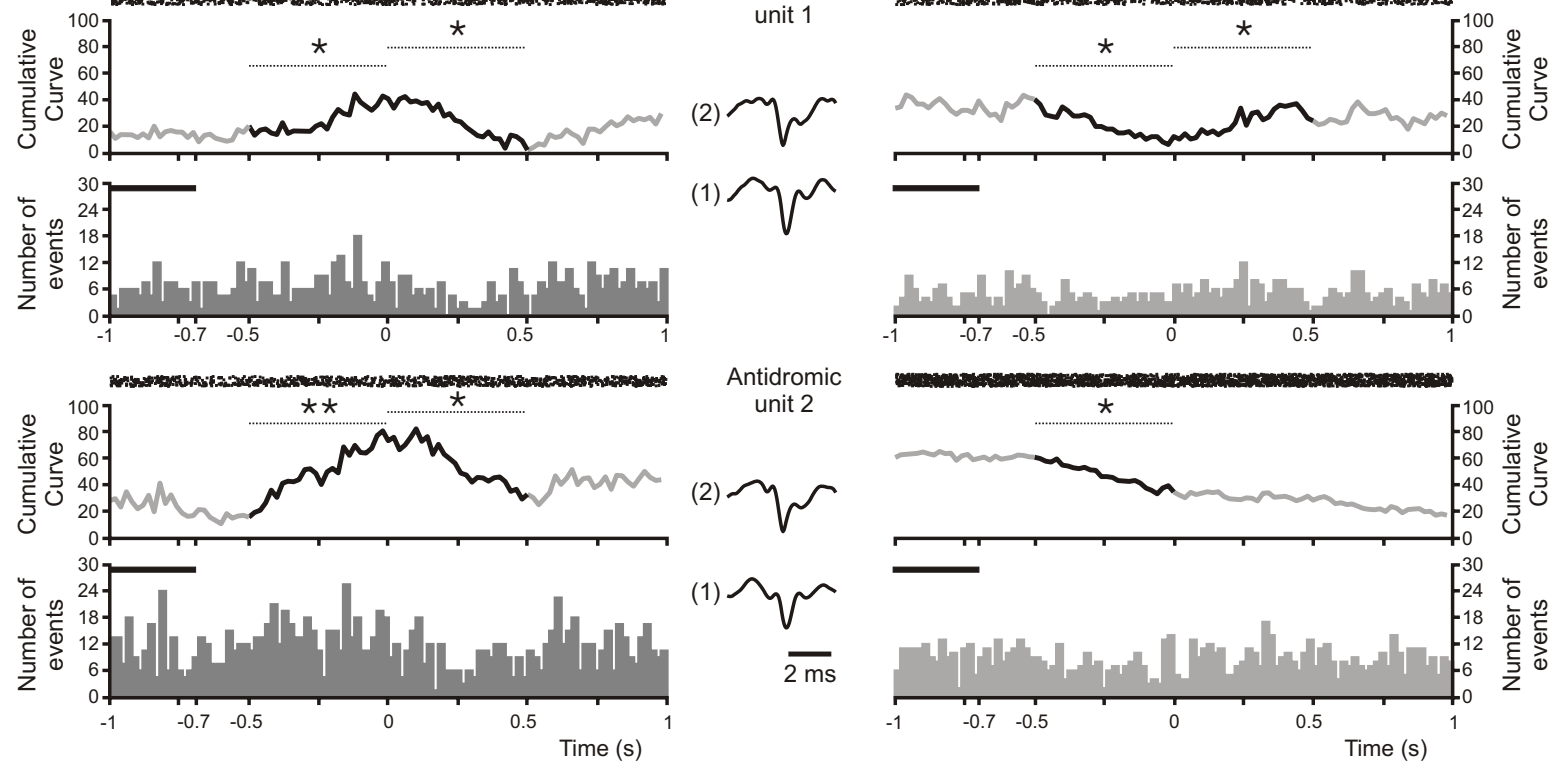

(1)

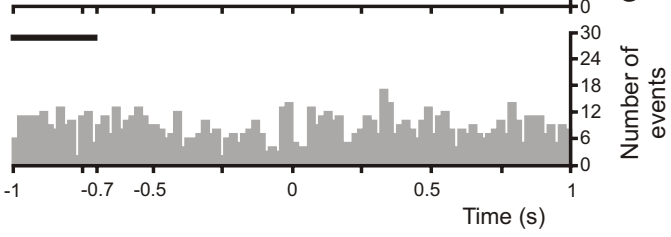

B

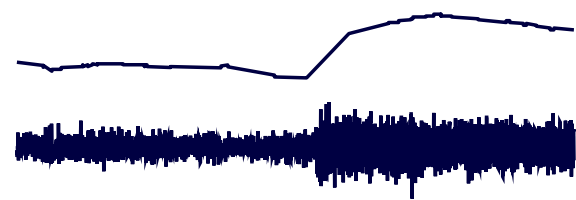

Mean Lev EMG Integral

Mean Lev EMG activity

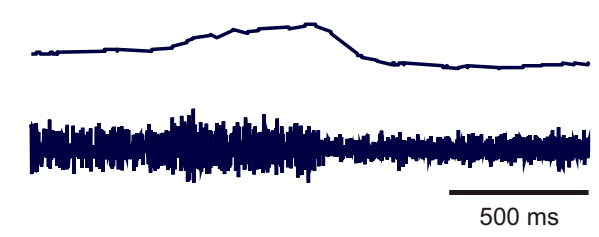

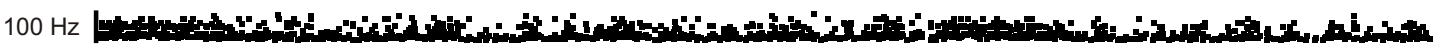

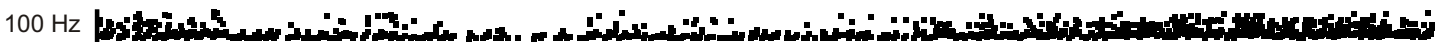
Lev EMG 
Le Ray et al, 2004

Figure 7

A

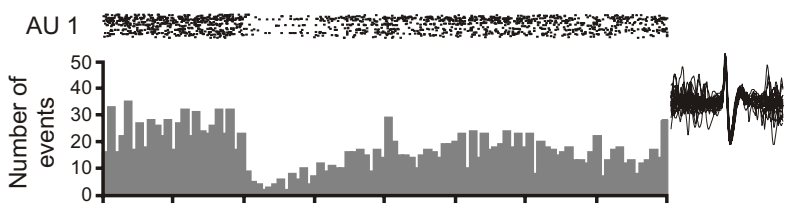

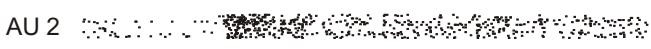

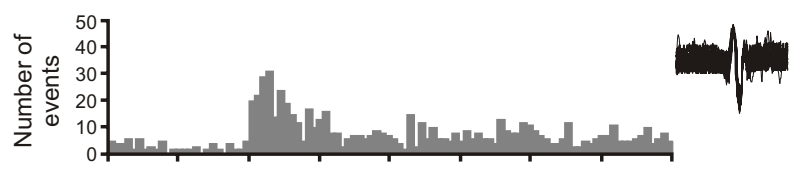

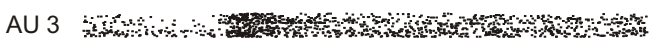
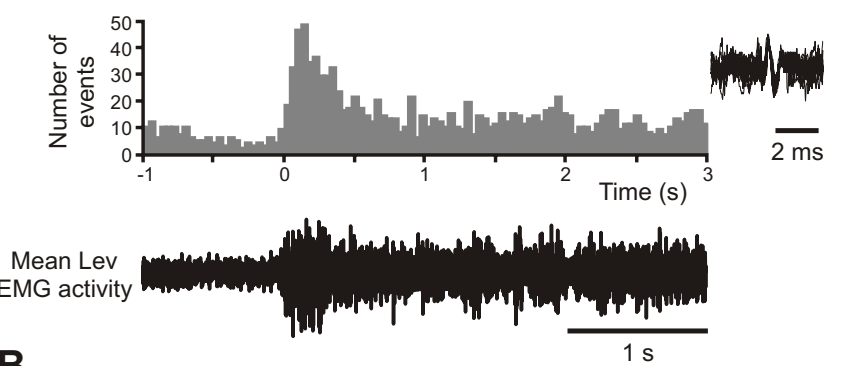

B

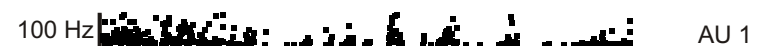

$100 \mathrm{~Hz}$

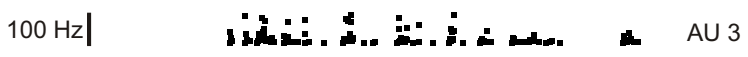

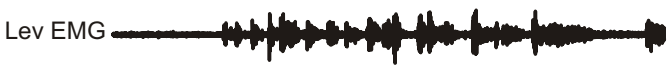

Lev EMG 
Figure 8
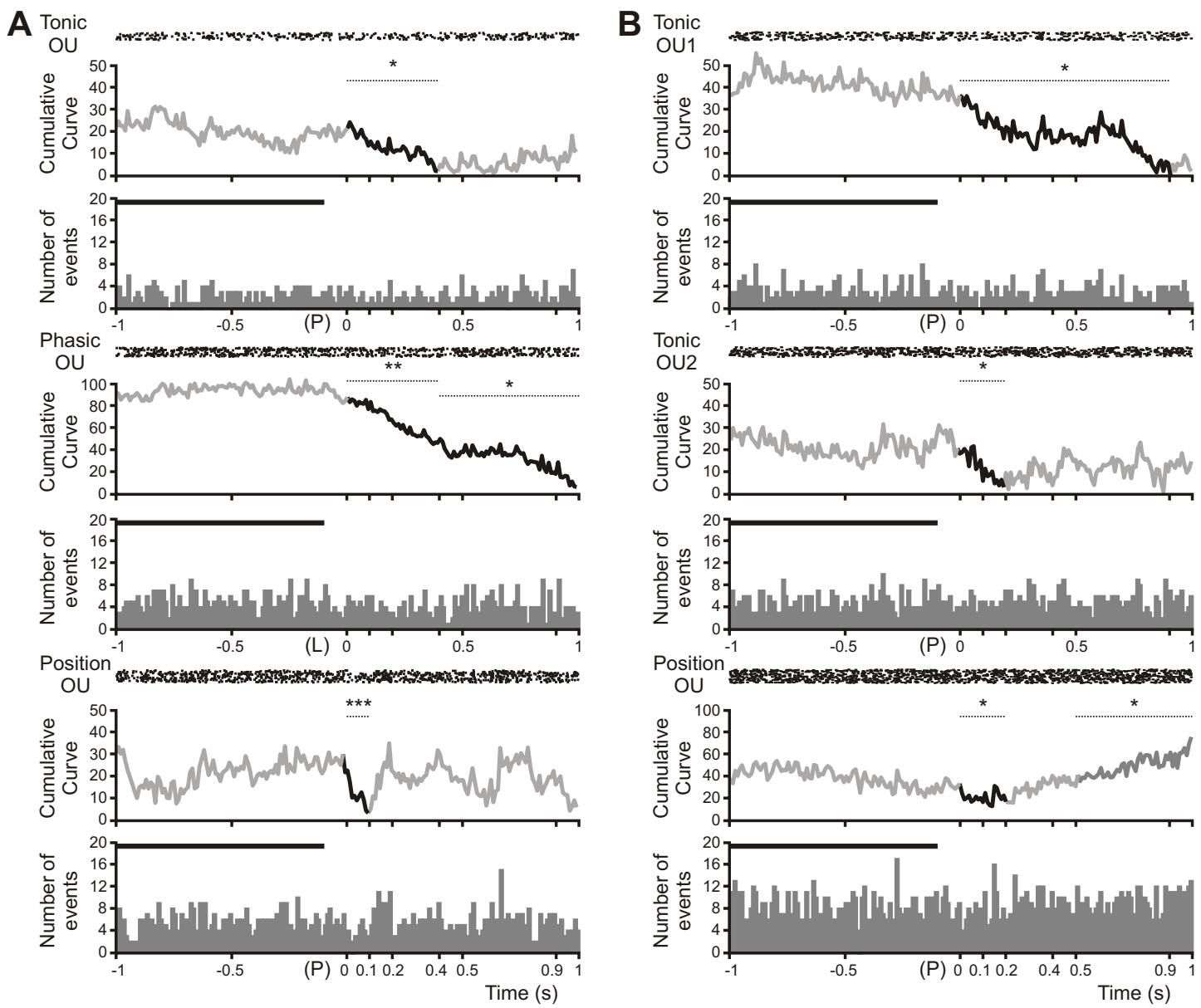
Le Ray et al, 2004

Figure 9

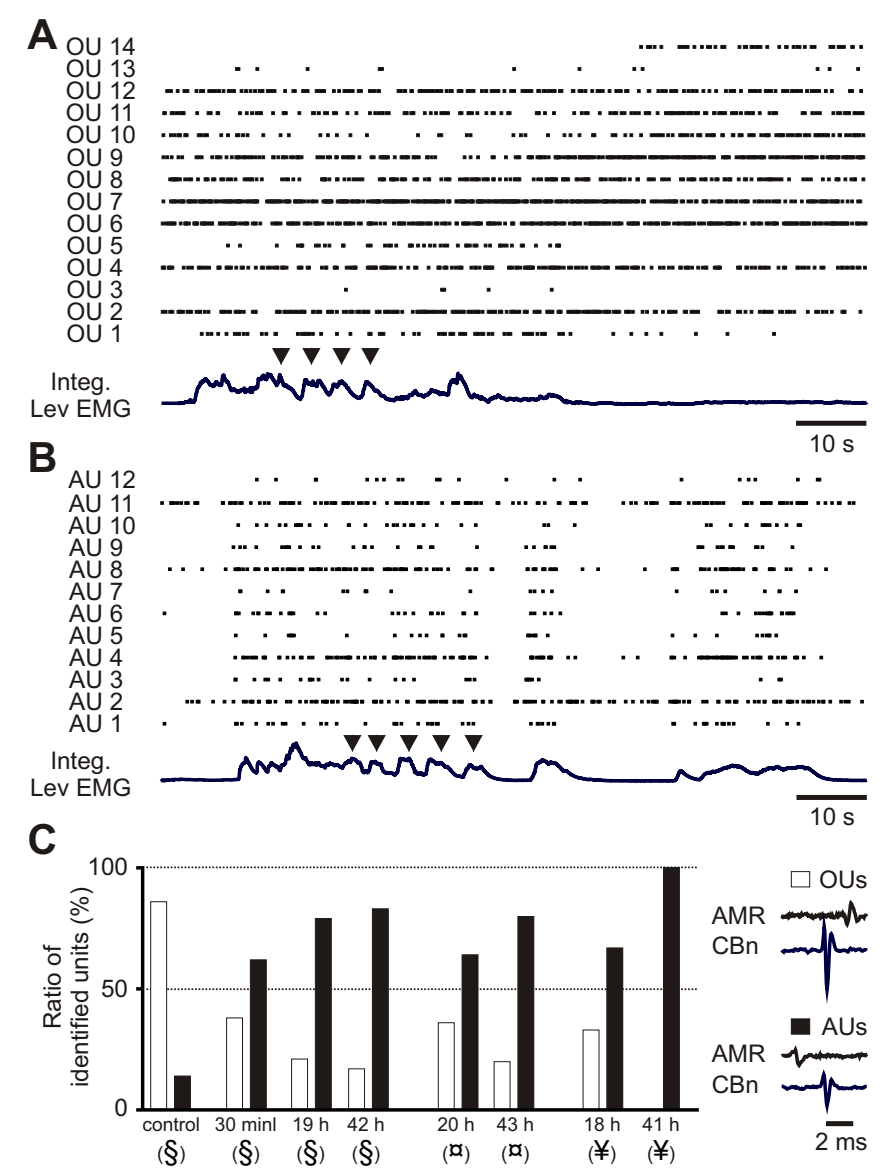




\begin{tabular}{|l|c|r|r|c|c|c|c|}
\hline \multirow{2}{*}{$\begin{array}{c}\text { Main phase } \\
\text { of firing }\end{array}$} & Total & Mean & \multicolumn{2}{c|}{ Main sensitivity } & \multicolumn{3}{c|}{ Decrease of tonic activity during } \\
\cline { 5 - 8 } & number & percentage & "velocity" (only) & and "position" & levation & presumed depression & none \\
\hline Levation & 156 & $43 \%$ & $16 \%$ & $84 \%$ & & & \\
\hline Presumed Depression & 17 & $5 \%$ & $0 \%$ & $100 \%$ & & & \\
\hline \hline Tonic units & 184 & $52 \%$ & & & $28 \%$ & $7 \%$ & $65 \%$ \\
\hline
\end{tabular}




\begin{tabular}{|c|c|c|c|c|c|c|}
\hline \multirow{2}{*}{$\begin{array}{c}\text { Main } \\
\text { type }\end{array}$} & Total & Mean & \multicolumn{2}{c|}{ Increase of firing at the onset of } & \multicolumn{2}{c|}{ Major decrease of firing at the onset of } \\
\cline { 5 - 7 } & number & percentage & levation & presumed depression & levation & presumed depression \\
\hline Locomotor & 62 & $40 \%$ & $85 \%$ & $15 \%$ & & \\
\hline postural & 93 & $60 \%$ & & & $84 \%$ & $16 \%$ \\
\hline
\end{tabular}

